\title{
Research Square \\ Optimization of Process Parameters during Hydroforming of Tank Bottom using NSGA-III Algorithm
}

Zaifang Zhang ( $\nabla$ zaifangzhang@shu.edu.cn )

Shanghai University

Feng Xu

Shanghai University

Xiwu Sun

Shanghai Aerospace Equipments Manufacture Co.LTD, Shanghai

\section{Research Article}

Keywords: Storage tank, Hydroforming, Kriging, NSGA-III

Posted Date: June 2nd, 2021

DOl: https://doi.org/10.21203/rs.3.rs-575709/v1

License: (1) This work is licensed under a Creative Commons Attribution 4.0 International License. Read Full License

Version of Record: A version of this preprint was published at The International Journal of Advanced Manufacturing Technology on January 8th, 2022. See the published version at https://doi.org/10.1007/s00170-021-08057-4. 


\title{
Optimization of Process Parameters during Hydroforming of Tank Bottom using NSGA-III Algorithm
}

\author{
Zaifang Zhang ${ }^{1} \cdot$ Feng $\mathrm{Xu}^{1} \cdot$ Xiwu Sun ${ }^{2}$ \\ (1. School of Mechatronic Engineering and Automation, Shanghai University, Shanghai 200444; \\ 2. Shanghai Aerospace Equipments Manufacture Co.LTD, Shanghai 200245)
}

\begin{abstract}
The hydroforming technology can realize overall forming of large storage tank's bottom, but the quality is affected by many technological parameters. In view of wrinkling and cracking defects of integral storage tank's bottom in hydroforming, a multi-objective optimization model is established for process parameters include pre-expansion pressure, hydraulic pressure, blank holder force and fillet radius of blank holder. Based on finite element simulation, the surrogate model between process parameters and quality criteria is established using Kriging technique. NSGA-III is used to determine optimal process parameters when storage tank's bottom reaches targets include minimum wall thickness variations, minimum fracture trend, minimum flange wrinkle and minimum wrinkle trend. Compared with Particle swarm optimization (PSO) algorithm, NSGA-III algorithm is more suitable to solve this optimization problem. The validity of this method and accuracy of the results are verified by simulation experiments.
\end{abstract}

Key words: Storage tank $\bullet$ Hydroforming $・$ Kriging $・$ NSGA-III

$\bowtie$ Zaifang Zhang

zaifangzhang@shu.edu.cn; 13901847320@163.com;

ORCID:0000-0002-1073-242X

\section{Introduction}

Launch vehicle is a kind of space delivery vehicle, which is usually used to send artificial earth satellites, manned spacecraft, space stations, space probes and other payloads into the predetermined orbit. The development of launch vehicle technology has promoted the development of Chinese satellites and their applications as well as manned space technology. The launch vehicle is composed of pressurized transportation, rocket body structure and telemetry control system. Rocket body structure carries all loads and propellants, mainly including propellant storage tank, the interstage section and the fairing. The reliability of rocket body structure determines the security and stability of the launch vehicle to a great extent. The propellant storage tank is the largest structural part in the rocket body structure. It is used as a pressure vessel to store liquid propellant, and at the same time as the main bearing structure of the carrier, supporting the thermal protection system and providing installation foundation and space for other system equipment. Therefore, the manufacturing quality of propellant tank is very critical.

The storage tank's bottom is a key component of propellant tank. It is a semi-ellipsoidal thin-walled shell and bears composite loads such as internal pressure and vibration. The traditional forming method is to first form melon parts, and weld them to get the integral storage tank's bottom. However, the performance of tailor-welded blanks is uneven, and mandatory assembly produces welding residual stress, which leads to poor reliability. In order to overcome shortcomings of traditional forming method, many studies have been conducted in recent years to develop and design new forming processes. Among these new technologies, sheet hydroforming (SHF) has been developed and used in the production of new generation of rocket tanks' bottoms.

SHF is a new soft mold forming method, which is not only beneficial to improve the forming quality, but also increases the limit drawing ratio (LDR) of the part. SHF uses liquid as the mold, which greatly simplifies mold structure and reduces production costs. It has been highly recognized and widely concerned in the stamping industry [1]. Nevertheless, due to the large size and thin wall of the storage tank's bottom (ratio of thickness to diameter equals $<3 \%$ ), wrinkling is induced by plastic instability in the forming of integral storage tank's bottom. In the hydroforming forming of the storage tank's bottom, various process parameters affect the final forming quality.

Process parameters in the hydroforming process are often chosen based on handbooks and 
trial-and-error approach. In order to reduce trial and error cost and shorten production cycle, many researchers have used statistical experimental methods to simulate the hydroforming process, explore theoretical models, and study the relationships between process parameters and forming quality. For example, Munoz-Rubio et al. [2] set process parameters as control factors and material parameters as noise factors, and found the optimal conditions for process control factors through taguchi method experimental design. Ballikaya et al. [3] used taguchi experimental design method to study the influence of mould angle, mould radius, punching force, blank holder force, cavity pressure and other process parameters on LDR. The results show that blank holder force has the greatest effect on LDR. Safari and Joudaki [4] used statistical tools including taguchi method and signal-to-noise ratio analysis) to obtain appropriate process parameters and produce parts with no defects. In addition, a nonlinear regression equation is established to predict the thickness variations ratio in hydrodynamics deep drawing and hydromechanical deep drawing processes.

Other models such as Barlat and Lian yield criterion, forming limit diagram (FLD) model and finite element model [5] are also used to simulate the hydroforming process. Alizad-Kamran and Hoseinpour-Gollo [6] proposed a theoretical model based on Barlat and Lian yield criteria to conduct fracture instability analysis with maximum drawing force conditions, and studied the influence of material and process parameters on the path of critical fluid pressure. Modi and Kumar [7] establish the regression equation between process parameters and objective functions based on the results of experiments and finite element analysis. Objective functions include minimum thickness and angular radius. Liu et al. [8] carried out mechanical analysis for the suspension area in hydroforming forming process of curved thin shell, and deduced nonlinear fluid pressure loading curve to suppress wrinkling and fracture. According to theoretical calculation of loading path and simulation results, the optimal fluid pressure loading path is obtained. Gajjar et al. [9] adopted two different yield criteria (Hill's quadratic model and Barlat's three-parameter model) to develop a stress-based FLD. They applied it to the failure prediction of AA5182 alloy square cup in hydraulic forming. Cai et al. [10] have built numerical simulation model for predicting plate thickness under fluid pressure. The wrinkling height is proposed to represent the anti-wrinkling property of the material. Cai et al. [11] found that the ratio between thickness and radius would affect errors in different areas of the cup. Chen et al. [12] explored the influence of die fillet size on the formability of parts by using finite element method. Nikhare et al. [13] presented a method to estimate the minimum pressure for low pressure hydroforming of non-buckling parts by using plastic energy principle. The model also shows that minimum pressure required depends on yield stress of the pipe, the thickness of the pipe and straight length of the section in contact with the die. Abdelkefi et al. [14] learned that finite element simulations using three-dimensional shell models could better predict thickness assessments. An experimental method for calculating friction coefficient is presented without using advanced numerical calculation method. Bagherzadeh et al. [15] realized precise modeling program for oil pressure's non-uniform distribution. Chen et al. [16] set up a theoretical model of the thin-walled shell's critical stress by using energy method, considering anti-bulging effect, so as to quantitatively predict and control the wrinkling of curved thin-walled shells in unsupported area. Wang et al. [17] calculated the processing window diagram using a stress analytical model with material properties. The result showed that initial pressure, total pressure and loading trajectory were basic parameters that directly affected forming quality and dimensional accuracy.

However, it is difficult to express the complex relationship between the quality and process parameters by theoretical model. Therefore, agent models have been widely used in design based on simulation. In addition to agent models, bionic heuristic algorithms for optimization are also becoming more and more popular for that they can produce the optimal solution in a reasonable calculation time. These studies mainly focus on the agent models and optimization algorithms.

Liu et al. [18] used response surface method to optimize the pre-expansion forming process. The results showed that the combination of pre-bulging effect and sheet metal hydroforming process is a potential method to improve the formability. Ozturk et al. [19] raised an improved AFEA-FCA method (adaptive finite element analysis and fuzzy control algorithm) to determine optimal hydraulic pressure and blank holder force, and obtain maximum ultimate drawing ratio. They also found that the coefficient of friction between plates and dies had little effect on optimizing loading profile. Chebbah et al. [20] put forward the optimization method of pipe hydroforming based on agent model and genetic algorithm. By comparing Kriging and moving least square (MLS) method, it is found that the optimal results obtained by Kriging method are better than MLS method. Bansch et al. [21] used meta-heuristic optimization model and finite element simulation for the complex process flow. The method can approximate the Pareto front through few finite element simulations. Hu et al. [22] came up with an improved NSGA-III optimization method, which can quickly and accurately solve a multi-objective optimization problem of sensor layout. Ben et al. [23] compared response surface method and least 
squares support vector regression (LSSVR) as meta-modeling techniques, to build a meta-model for global sensitivity analysis and multi-objective optimization of THF processes. Ge et al. [24] proposed a multi-objective optimization method based on differential evolution to obtain the best match between internal pressure and end feed process. The validity, accuracy and reliability of this method are proved by an example of pre-bending hydroforming. Hashemi et al. [25] proposed an optimization method combining adaptive simulated annealing technique and adaptive finite element method. Experimental results showed that proposed adaptive method can be used for process optimization of large search space. Huang et al. [26] used the Kriging method to build proxy model for loading path design of T-tube hydroforming, and the robustness and reliability of this method were verified. Intarakumthornchai et al. [27] integrated genetic algorithms into finite element analysis for determination of feasible loading paths.

The application of simulation in hydroforming process can help engineers to develop process effectively, thus reducing cost and limitations of real experiments. The combination of finite element method with various optimization methods can avoid too much time on trial-and-error experiment. Therefore, this paper uses mathematical prediction model to model the hydroforming forming process of the storage tank's bottom, explores the relationship between quality indicators and process parameters, and finally obtains the best process parameters to achieve the best quality. The rest of this article is as follows: Section 2 describes and models the problem. Section 3 focuses on the simulation and prediction model through Kriging interpolation method. Section 4 uses NSGA-III algorithm for multi-objective optimization, the best process parameters of forming process are obtained. Compared with Particle Swarm Optimization (PSO), the accuracy of optimization results is verified by experiments. Section 5 summarizes the whole paper and puts forward some questions that need further study.

\section{Model of storage tank's bottom during hydroforming}

The forming processes of the storage tank's bottom is basically divided into two steps :(1) the punch keeps still, and the liquid chamber provides a certain pre-expansion force, so that the sheet is extruded and deformed upward and anti-expansion zone is formed. (2) The punch begins to go down, driving the sheet downward and blank is deformed. Under double action of punch and liquid chamber pressure, the bottom of storage tank is finally formed.

Many kinds of requirements should be taken into account in the forming of the storage tank's bottom, and sometimes they are contradictory, so several objective functions are introduced. The optimization objective is to find the best process parameters which can achieve optimal forming quality. According to relevant literature and engineering experience, the process parameters we choose are pre-expansion pressure $P_{0}$, hydraulic pressure $P$, blank holder force $F$ and the fillet radius of blank holder $R_{h}$. Under these conditions, the nonlinear optimization problem can be expressed as follows:

$$
\left\{\begin{array}{l}
y 1=\min \left(\theta_{\max }\right) \\
y 2=\min \left(-P_{\min }\right) \\
y 3=\min \left(U 2_{\max }\right) \\
y 4=\min \left(Q_{\max }\right) \\
y 1 \leq 20 \% \\
y 2 \leq 1.2 t \\
\text { with } \\
X^{L} \leq X \leq X^{U}
\end{array}\right.
$$

Where is the objective function, where $t$ is initial thickness, $X$ is the vector of design variable: $X=\left[P_{0}, P, F, R_{h}\right]$. This vector is bounded by $X^{L}$ and $X^{U}$ which, respectively represent lower and upper limits: $X^{L}=[0,0,1200,10]$ and $X^{U}=[3,12,2400,100]$.

In our case, the optimization problem has four objectives. Objective functions 1 and 2 are defined to avoid cracking problem. Cracking is a major defect in the bottom of storage tank. The fracture is evaluated by sheet thickness and FLD. The change of sheet thickness can reflect severity of rupture, and the maximum thinning rate can more visually represent change in thickness of the sheet during the forming process. Objective functions 3 and 4 are defined to reduce wrinkling. Wrinkling is the main form of compression instability caused by compressive stress in sheet metal forming. Wrinkling is evaluated by height of wrinkling and thick strain. The wrinkling height truly reflects the severity of the parts' wrinkling defects, while maximum thickness strain can reflect the tendency of the sheet 
wrinkling during the forming process. During forming process, wrinkles usually occur in the flange region and the side wall. Since the workpiece in this paper is spherical, main form of wrinkling is flange side wrinkling without side wall wrinkling, so this paper mainly considers flange side wrinkling.

The specific objective functions are explained as follows:

\section{Objective function 1:}

This function is defined to avoid rupture. It is generally required in industry that maximum thickness reduction rate is less than $20 \%$ for qualified parts. Maximum thickness thinning rate is defined as follows:

$$
\theta_{\max }=\frac{t_{0}-t_{\min }}{t_{0}} \times 100 \%
$$

Where $\theta_{\max }$ is the maximum thinning ratio, $t_{0}$ is the initial plate thickness, $t_{\min }$ is the smallest plate thickness. So objective function 1 is defined as:

\section{Objective function 2:}

$$
y 1=\min \left(\theta_{\max }\right)
$$

In the field of metal forming, FLD is used to judge failure of materials. It shows the limits of sheet during forming under different stress states. FLD figure takes minimum principal strain in plane strain state as abscissa, and maximum principal strain in plane strain state as ordinate, includes a forming limit curve (FLC) formed by all the forming limit points. If plane principal strain of a point on the sheet is above FLC, the sheet where the point is located will crack. If plane principal strain of a point on the sheet is below FLC, deformation state of the point is safe, and the farther from FLC, the greater the safety margin.

FLC of 2219 aluminum alloy is obtained through theoretical derivation. The premise of theoretical derivation is:

(1) Von.Mises yield criterion

The research object is large and thin-walled shell. For a thin-walled shell, thickness stress $\sigma_{Z}$ is very small and can be approximately regarded as: $\sigma_{Z}=0$. Therefore, the shell can be considered to be in a plane stress state, i.e., $\sigma_{3}=\sigma_{Z}=0$. Then the Von.Mises yield criterion can be expressed as:

$$
\left(\sigma_{1}-\sigma_{2}\right)^{2}+\sigma_{2}^{2}+\sigma_{1}^{2}=2 \sigma_{s}^{2}
$$

(2) Hollomon hardening criteria

Hollomon hardening criterion is the most classical constitutive equation, on which most other constitutive equations are derived. It can well describe the stress-strain relationship of most metals, and it is widely used in engineering. Therefore, the theoretical calculation in this paper adopts Hollomon hardening criterion, and it be expressed as:

$$
\sigma=K \varepsilon^{n}
$$

(3) Swift-Hill instability criterion

The Von.Mises yield criterion and Hollomon hardening criterion can describe stress-strain rule of the material under deformation. The instability criterion can be used to judge whether the material fails or not. There are many researches on plastic tensile instability theory of sheet, among which Swift dispersed instability criterion and Hill concentrated instability criterion are the most widely used. The specific formulas are shown in Eqs. (6) and (7).

$$
\begin{gathered}
\left\{\begin{array}{l}
\frac{d \sigma_{1}}{d \varepsilon_{1}}=\sigma_{1} \\
\frac{d \sigma_{2}}{d \varepsilon_{2}}=\sigma_{2}
\end{array}\right. \\
\frac{\mathrm{d} \sigma_{1}}{\sigma_{1}}=\frac{d \sigma}{\sigma_{2}}=-d \varepsilon_{3}
\end{gathered}
$$

Where $\sigma_{1}, \sigma_{2}$ are principal stresses in the plane, and $\varepsilon_{1}, \varepsilon_{2}, \varepsilon_{3}$ are principal strains. The Swift-Hill instability criterion is chosen in order to comprehensively describe the failure state of sheet. Assume that $\sigma_{1} \geq \sigma_{2} \geq 0, \quad \alpha=\frac{\sigma_{2}}{\sigma_{1}}$, thickness direction stress $\sigma_{3}=0$. Then, combining with Eqs. (4), (5), (6) and (7) above, the ultimate strain values of sheet can be calculated by substituting relevant mechanical property parameters of materials with different values of $\alpha$. The ultimate strain values are shown in Table 1. According to the calculated values in the table, these limit strain points are drawn in coordinate system $\varepsilon_{1}-\varepsilon_{2}$, and a smooth curve is fitted by Origin software. Thus, the theoretical FLC of 2219 
aluminum alloy is obtained.

Table 1 Strain data of Swift-Hill

\begin{tabular}{ccccc}
\hline \multicolumn{2}{c}{ Swift } & & \multicolumn{3}{c}{ Hill } \\
\hline$\alpha$ & $\varepsilon_{1}$ & $\varepsilon_{2}$ & $\varepsilon_{1}$ & $\varepsilon_{2}$ \\
0 & & & 0.528 & -0.264 \\
0.1 & & & 0.456 & -0.192 \\
0.2 & & & 0.396 & -0.132 \\
0.3 & & & 0.3452 & -0.0812 \\
0.4 & & & 0.3017 & -0.0377 \\
0.5 & 0.264 & 0 & 0.264 & 0 \\
0.6 & 0.2832 & 0.0405 & & \\
0.7 & 0.3009 & 0.0926 & & \\
0.8 & 0.308 & 0.154 & & \\
0.9 & 0.2959 & 0.2152 & & \\
1.0 & 0.264 & 0.264 & & \\
\hline
\end{tabular}

Swift instability criterion describes the dispersive instability characteristic of sheet under biaxial tensile condition. Hill instability criterion is more suitable for uniaxial tensile stress state and plane tensile stress state. Therefore, when the range of $\alpha$ is $0-0.5$, theoretical value of the material's ultimate strain at the time of instability can be obtained by using the Hill concentrated instability criterion. When the range of $\alpha$ is $0.5-1.0$, theoretical value of the material's ultimate strain at the time of instability can be obtained by using Swift dispersed instability criterion. When $\alpha=0.5$, average value of the two limiting strains is chosen to obtain the complete theoretical FLC. Fig. 1 shows the complete FLC.

$\left\{\begin{array}{l}\varepsilon_{1}=0.264-\varepsilon_{2} \quad, \varepsilon_{2} \leq 0 \\ \varepsilon_{1}=0.263+0.493 \varepsilon_{2}+0.809 \varepsilon_{2}^{2}-22.724 \varepsilon_{2}^{3}+40.676 \varepsilon_{2}^{4}+216.524 \varepsilon_{2}^{5}-717.605 \varepsilon_{2}^{6}, \varepsilon_{2}>0\end{array}\right.$

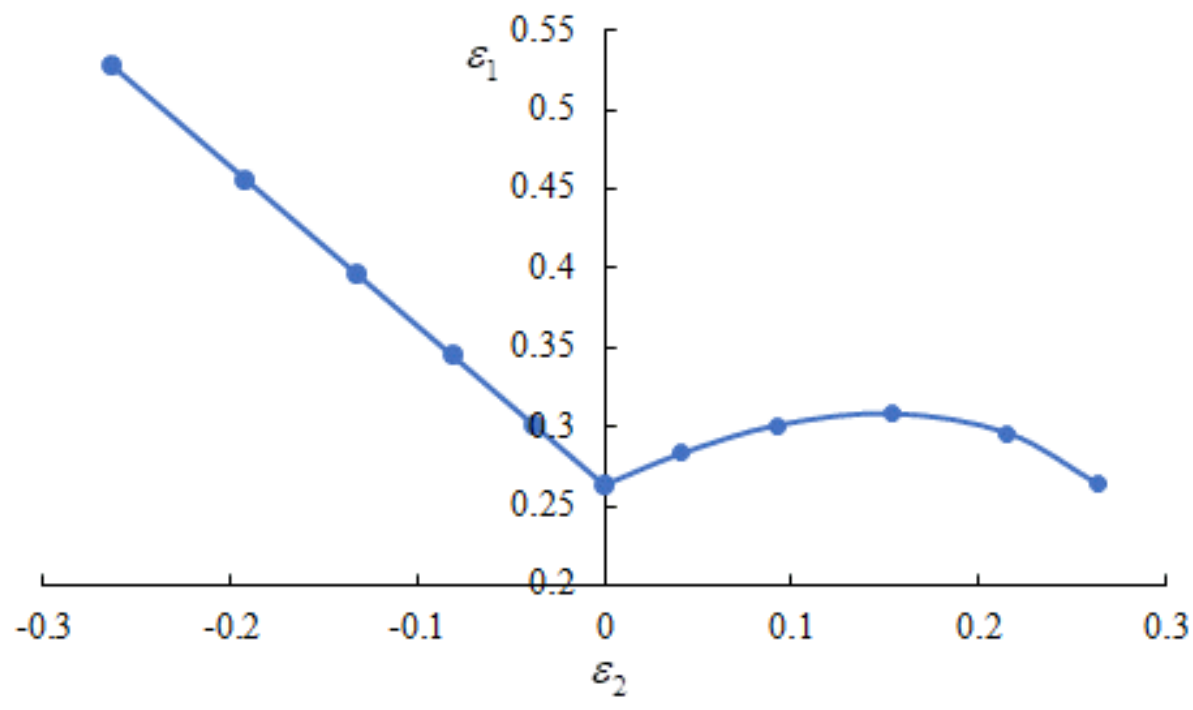

Fig. 1 Theoretical FLC of 2219 aluminum alloy

There are many reasons for the cracking of sheet hydroforming, while FLD describes ultimate strain of sheet's cracking under different conditions. When the point's principal strain falls above the FLC curve, the part will break when it is formed. When the point's principal strain is below the FLC curve, the farther away the point is, the safer it is. Suppose that the point's principal strain is $\left(\varepsilon_{2}^{i}, \varepsilon_{1}^{i}\right)$, and the vertical distance from this point to the FLC is $P$, then $P=\varepsilon_{F L D}^{i}-\varepsilon_{1}^{i}$. In order to prevent the whole part from fracture, the principal strain of all points should be below the FLC, and the larger P is, the better. Then objective function 2 can be expressed as:

\section{Objective function 3:}

$$
y 2=\max \left(P_{\min }\right)
$$


When the sheet is wrinkling, the blank holder will be jacked up, so the degree of wrinkling can be represented by measuring vertical displacement of the flange area $U 2$. Industry requires that wrinkle height should be less than 1.2 times the thickness of the sheet. To minimize wrinkling, U2 needs to be as small as possible. Objective function 3 can be expressed as:

$$
\mathrm{y} 3=\min \left(U 2_{\max }\right)
$$

\section{Objective function 4:}

Under the condition of plane strain, $\varepsilon_{\max }+\varepsilon_{\min }+\varepsilon_{t}=0$. Then $\varepsilon_{t}=-\left(\varepsilon_{\max }+\varepsilon_{\min }\right) . \varepsilon_{t}$ is the thick strain. When $\varepsilon_{\mathrm{t}} \geq 0$, the sheet has a wrinkle trend. $\varepsilon_{\max }=-\varepsilon_{\min }$ can be defined as a wrinkling curve. When the point is below the wrinkling curve, the sheet has a wrinkle trend. Suppose that the principal strain of a point is $\left(\varepsilon_{2}^{\mathrm{i}}, \varepsilon_{1}^{i}\right)$, the vertical distance from this point to the wrinkling curve is $Q$, then $Q=\varepsilon_{\max }^{i}-\varepsilon_{1}^{i}$. In order to reduce the tendency of sheet's wrinkling, $Q$ of each point in the forming part should be as small as possible. Objective function 4 can be expressed as:

$$
y 4=\min \left(Q_{\max }\right)
$$

\section{Experimental design and prediction model}

In multi-objective optimization problem, in order to shorten optimization period, reduce optimization cost and obtain appropriate optimization scheme, we first need to build an agent model. This requires a complete numerical analysis of the hydroforming process, and then an agent model based on Latin hypercube sampling method is established. Finally, a multi-objective optimization algorithm is used to achieve the optimal parameters with low cost and high precision. Several agent models can be used to approximate the nonlinear optimization problem Eq. (1). Here, Kriging interpolation method is adopted. The flow chart of optimization process is shown in Fig. 2.

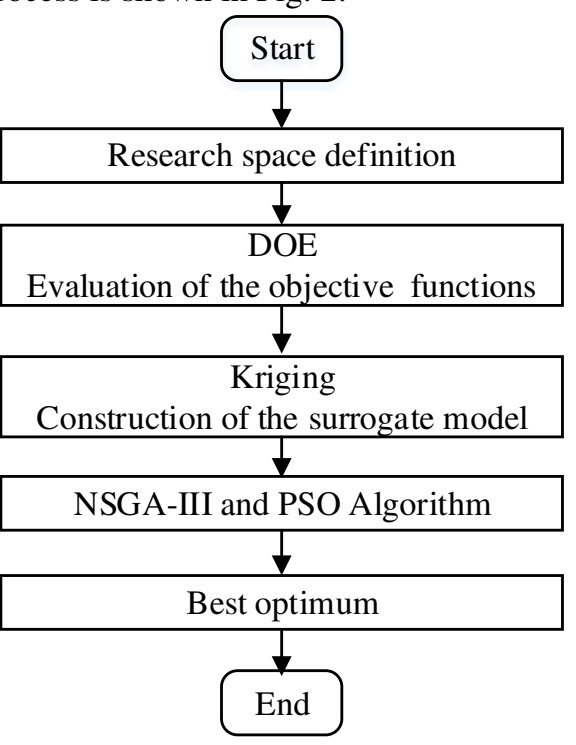

Fig. 2 Flowchart of optimized design

\subsection{The numerical simulation}

The simulation about the hydroforming process of the storage tank's bottom is specially treated, according to characteristics of the hydroforming process. The material of sheet is 2219 aluminum alloy, which is isotropic elastic-plastic and meets Mises yield criterion. The thickness of sheet has 5 Simpson integral points and the unit type is S4R, i.e., shell unit. In order to improve computational efficiency, $1 / 4$ model is selected for process simulation. Symmetric boundary conditions are applied at the plane of symmetry. The plate is set as a variable body, punch, die and blank holder are set as rigid bodies, and friction coefficient at each contact surface is set as 0.1 . In order to study the influence of process parameters on the plate, a denser mesh is used for the plate. The mesh of sheet is divided into quadrangles and the grid size is set as 4 . The punch, die and blank holder mesh are divided into quadrangles and the grid size is set as 6 .

Fig. 3 and Table 2 give the geometric parameters, material properties and process parameters used in the simulation and experiment. In Fig. $3, D_{0}, D_{p}, D_{\mathrm{h}}$ are the diameters of the blank, punch and blank 
holder, respectively. $t$ is the initial thickness of the blank. $R_{\mathrm{h}}, R_{d}$ are the fillet radius of the blank holder and the die, respectively.

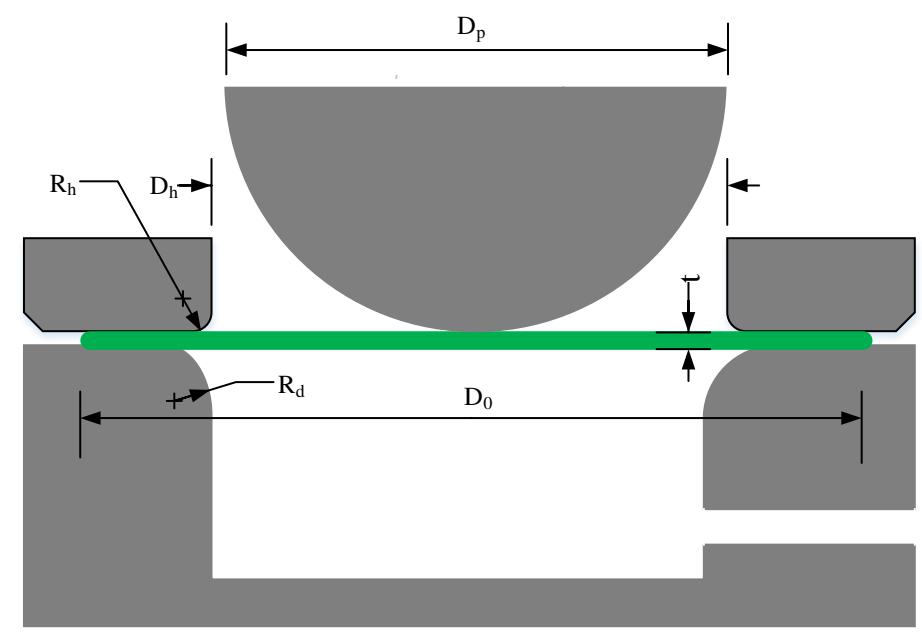

Fig. 3 Geometrical parameters of a storage tank's bottom

Table 2 Material and process conditions

\begin{tabular}{llll}
\hline Geometrical parameters & & \multicolumn{2}{c}{ Material properties (2219 aluminum alloy) } \\
\hline$D_{0}$ & $4200 \mathrm{~mm}$ & $\mathrm{E}$ & $73.8 \mathrm{GPa}$ \\
$\mathrm{D}_{\mathrm{p}}$ & $3338 \mathrm{~mm}$ & $\mathrm{~K}$ & $564 \mathrm{MPa}$ \\
$\mathrm{D}_{\mathrm{h}}$ & $3340 \mathrm{~mm}$ & $\mathrm{n}$ & 0.264 \\
$\mathrm{t}$ & $8 \mathrm{~mm}$ & Process parameters & \\
$\mathrm{R}_{\mathrm{h}}$ & $100 \mathrm{~mm}$ & Coulomb friction coefficient & 0.1 \\
$\mathrm{R}_{\mathrm{d}}$ & $50 \mathrm{~mm}$ & Total axial feeding & $900 \mathrm{~mm}$ \\
\hline
\end{tabular}

In order to analyze the influence of process parameters in hydroforming, the same loading path is adopted in the simulation process, and objective functions are obtained under the same conditions. Otherwise, changing process parameters will completely change forming conditions, which will complicate the model construction based on finite element. Figure 4 depicts the loading paths of stroke and hydraulic pressure used in the analysis. Keep the punch still, apply a certain pre-expansion pressure at the sheet, and the sheet deforms. Then the punch is linearly loaded, and the pressure remains linearly loaded. Geometric parameters are fixed parameters, as shown in Table 2. The design variables are pre-expansion pressure $P_{0}$, hydraulic pressure $P$, blank holder force $F$ and the fillet radius of blank holder $R_{h}$. Their initial values are $1 \mathrm{MPa}, 3 \mathrm{MPa}, 1500 \mathrm{t}$ and $100 \mathrm{~mm}$, respectively.

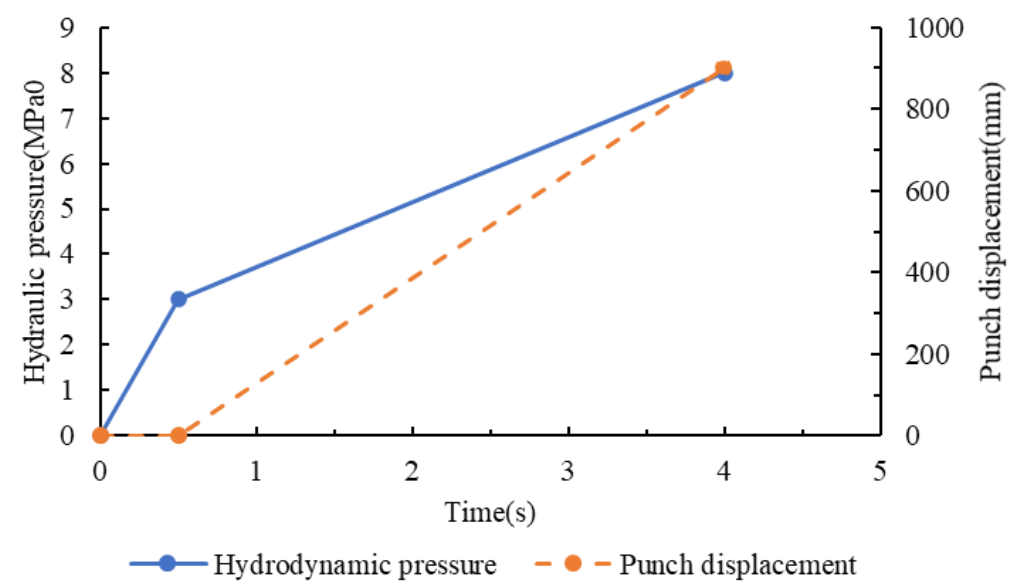

Fig.4 Loading path of hydraulic pressure

Finally, the hydroforming forming model of the storage tank's bottom is obtained as shown in Fig. 5. 


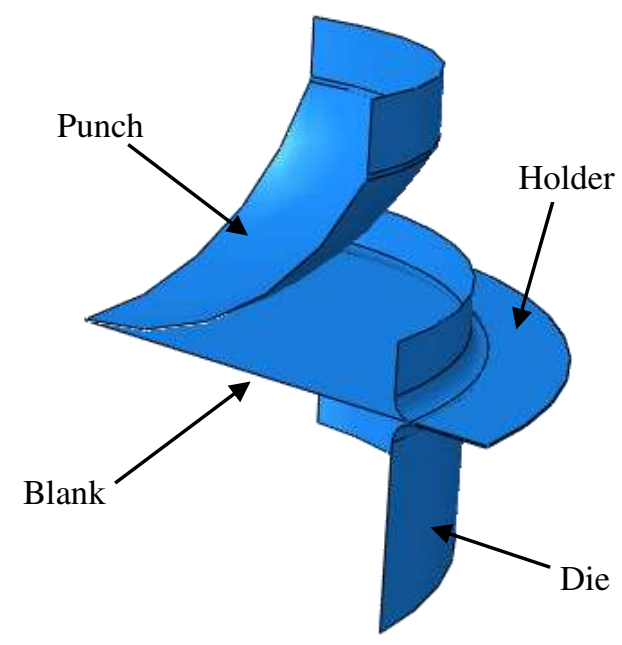

Fig. 5 Finite element model of the storage tank's bottom

\subsection{Establishment of prediction model}

In this paper, Kriging method is used to build an approximate model. Kriging treats the response $\mathrm{y}(\mathrm{x})$ of the simulation model as an implementation of a random process that includes regression terms. The method is applied to actual work to express response surface in explicit form according to the optimization variables. The approximate relation of the objective function can be expressed as follows:

$$
J(x)=p^{T}+Z(x)
$$

Kriging is used to fit the actual experimental value and the predicted value, and it is necessary to check the fitting accuracy of the approximate model. Only when certain conditions are met, the approximate model can be used in engineering design. The accuracy verification of approximate model includes two aspects: prediction ability at sample points and reproducibility ability at non-sample points. Since the Kriging approximation model is interpolation approximation, there is no error at the sample points. Then, cross-validation method is used to test accuracy of agent model without generating additional sampling points. The indexes of cross validation include determination coefficient $\mathrm{R}^{2}$, mean square error (MSE). For our Kriging agent model, the optimal determination coefficient $\mathrm{R}^{2}$ are $(0.9370,0.9075,0.9419,0.9271)$, which are greater than 0.9 , indicating that Kriging can fully explain the most variability response variables. The MSE of Kriging agent model are $(7.749 \%, 9.907 \%, 7.261 \%, 8.235 \%)$. The MSE are less than $10 \%$, which further confirms the adequacy of the prediction model. The goodness of fit of the prediction model is shown in Fig. 6. It can be seen from Fig. 6 that the deviation between most of the predicted data points and the experimental data points is very small, indicating that the model can successfully interpolate the nonlinear mapping between the response variables and the process parameters. In conclusion, the agent model has high accuracy and can be used in the optimization process next.

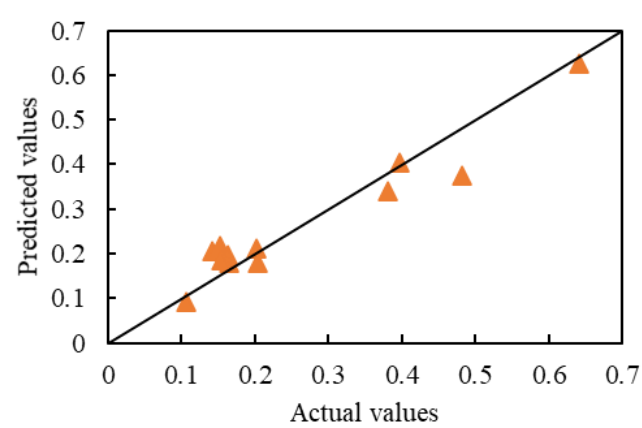

(a) $\mathrm{y} 1$

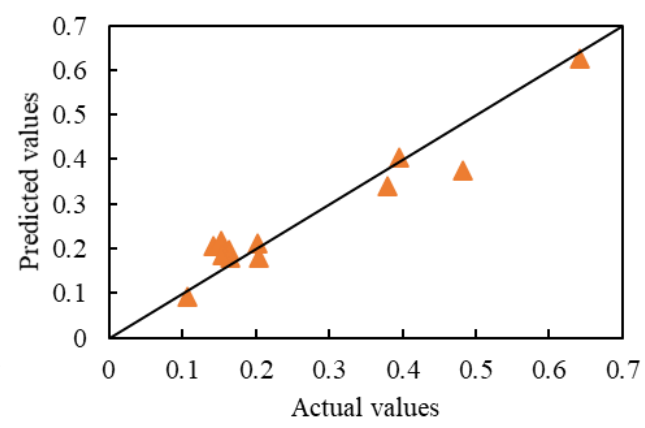

(b) y2 


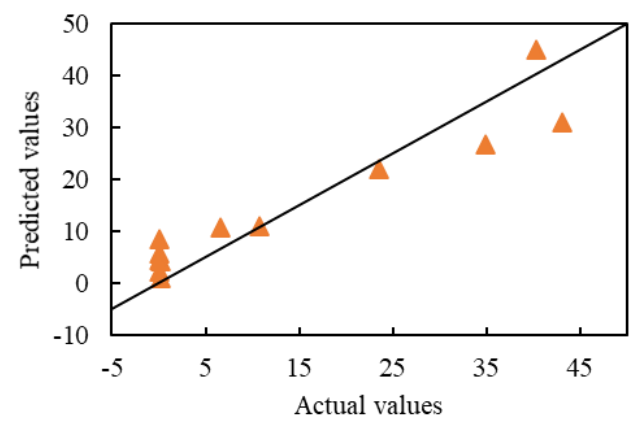

(b) y3

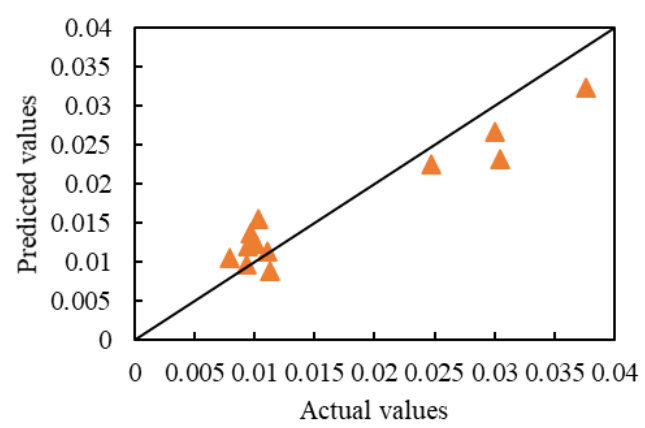

(d) y4

Fig. 6 The goodness-of-fit plot of Kriging

\subsection{The influence of process parameters on response variables}

The influence of process parameters on response variables can be observed in the pareto diagram, as shown in Fig. 7. The effect of parameters on the response is proportional to the band length. When the band length exceeds 0.05 , the effect is statistically significant. The blue bands represent a synergistic effect, while the red bands represent an antagonistic effect. The pareto diagram shows that the quality of the storage tank's bottom is highly dependent on the hydraulic pressure. The pareto diagram also shows that the process parameters have some influence on the response.

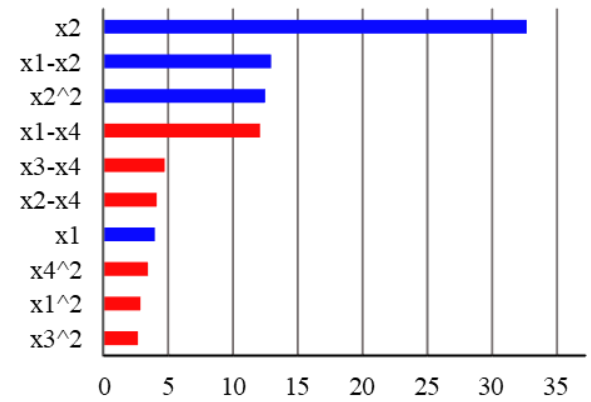

(a)\% effect on y1

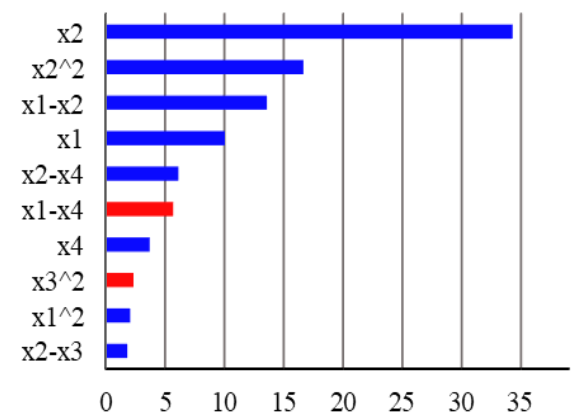

(c) \% effect on y3

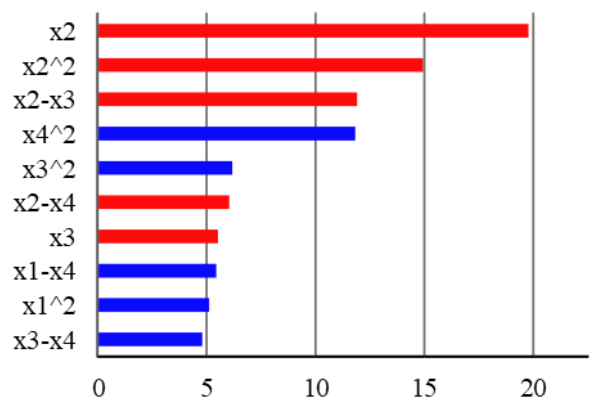

(b) $\%$ effect on y2

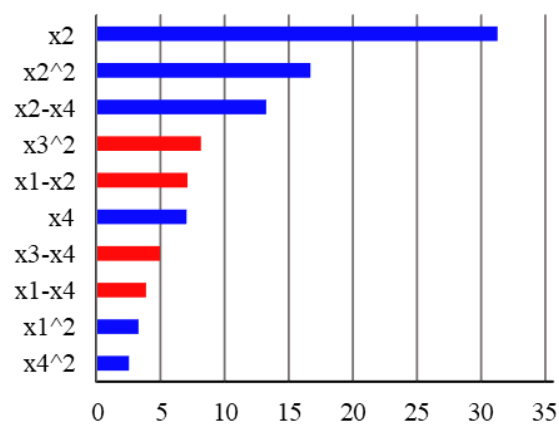

(d) $\%$ effect on y4

Fig. 7 Pareto diagram showing the relative influences of process parameters $X$ on the response variable

\section{Multi-objective optimization and result analysis}

The quality optimization of storage tank's bottom is a multi-objective optimization problem, and there is a mutual restriction relationship between the objectives, so this paper uses NSGA-III algorithm to solve the problem. As a meta-heuristic algorithm, the crossover and mutation operations of NSGA-III algorithm ensure the diversity of solutions, and the reference point selection strategy improves the speed of searching solutions.

\subsection{NSGA-III algorithm}

In the pseudo-code of NSGA-III, the detailed steps are shown in Table 3:

Step 1: Lines 1-2, initializes the population of chromosomes, each chromosome represents a solution of 
process parameters. Set stop criteria.

Step 2: Lines 4-5, performs the crossover and mutation operations and generates a new population.

Step 3: Line 6, performs the evaluation operation. The old and new populations are combined into a temporary population, and the fitness values of each chromosome for all objective functions are evaluated.

Step 4: Lines 7-17, performs a quick non-explicit sort.

Step 5: Lines 18-21, uses the reference point strategy to direct the search.

Step 6: Go to step 2, until the stop conditions are satisfied.

Table 3 Algorithm NSGA-III

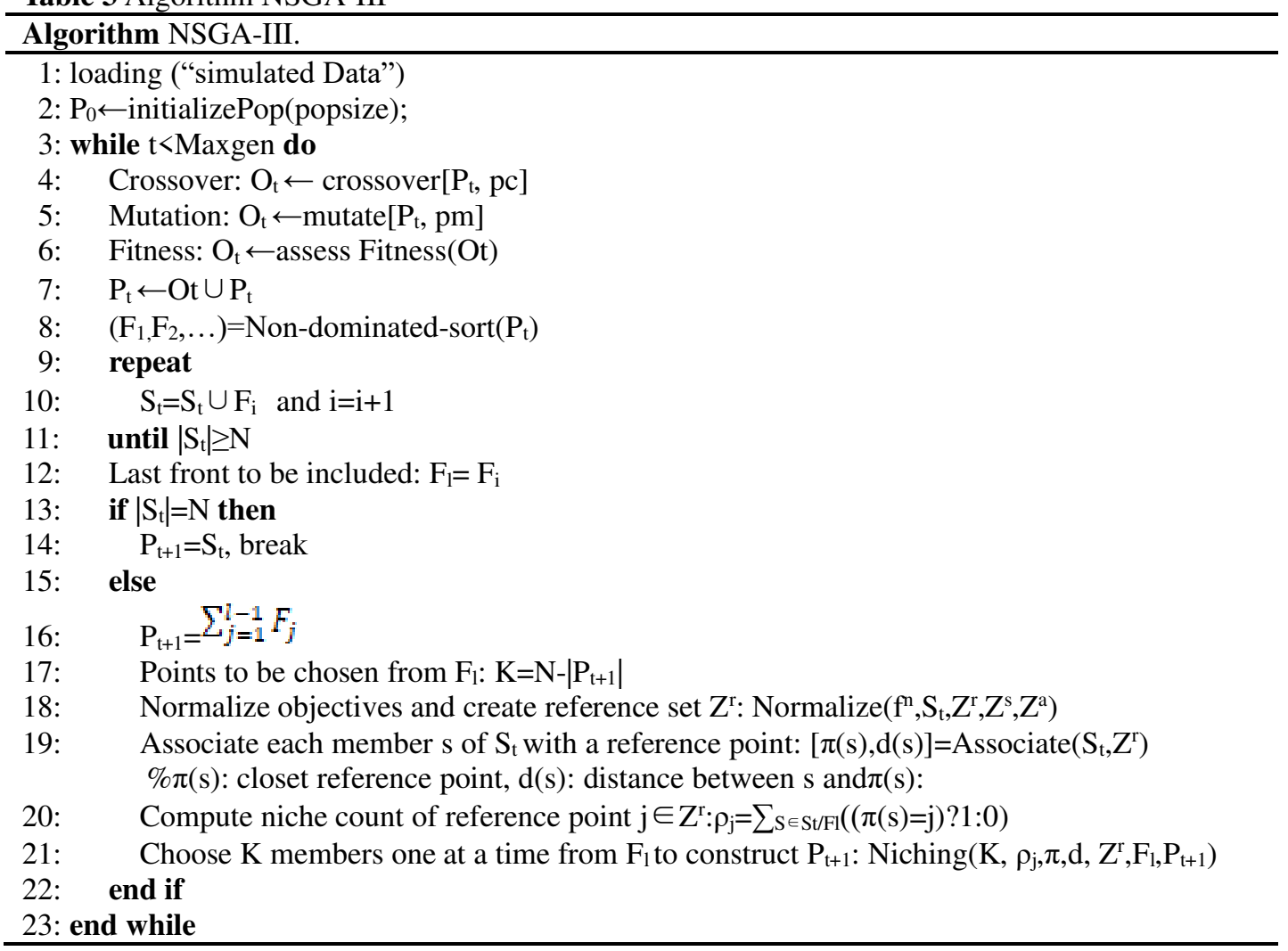

\subsection{Optimization results and analysis}

In our study, the parameters of NSGA-III algorithm are set as follows: parameters of population size, crossover probability, mutation probability, crossover parameter and mutation parameter are chosen as $100,0.85,0.15,20$ and 20, respectively. The optimization process is repeated 50 times. The search process for each trial will continue until the predefined maximum number of 500 generations is met. In order to verify the accuracy of optimization results of NSGA-III algorithm, PSO algorithm is selected as comparison. PSO algorithm can also be used to deal with multi-objective optimization problems, but the selection mechanism is different. PSO algorithm find the optimal solution through the collaboration and information sharing between individuals in the group. PSO algorithm is easy to fall into local convergence while NSGA-III algorithm searches the problem space more random and uniform. Parameters of the PSO algorithm are set as follows: population size, inertia weight and learning factor are chosen as 100, 0.9 and 0.9 , respectively.

Fig. 8 shows the change curve of the four objective functions' optimal values when the number of iterations is 40 . It can be seen that the fitness value gradually decreases with the increase of the number of evolutionary iterations. Generally speaking, NSGA-III algorithm and PSO algorithm converge. It can also be seen from Fig. 8 that NSGA-III algorithm converges faster than PSO algorithm, and the values of the objective function found by NSGA-III algorithm is smaller than PSO algorithm within 40 iterations. 


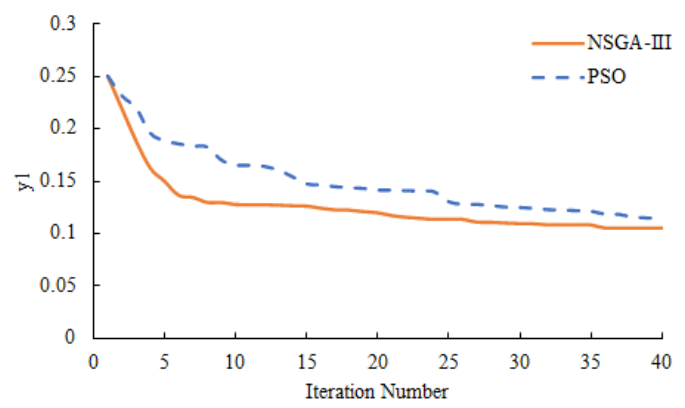

(a) $\mathrm{y} 1$

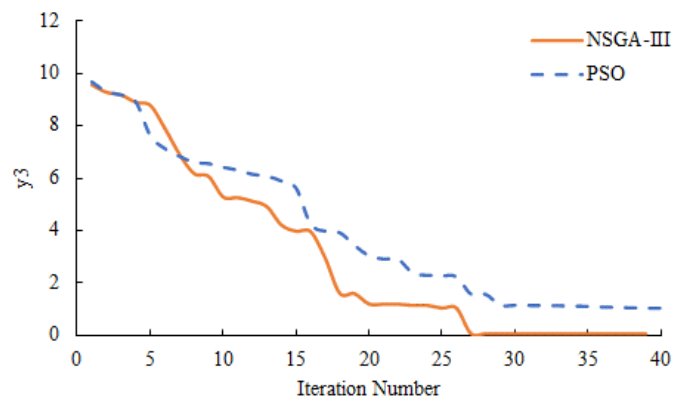

(b) $\mathrm{y} 3$

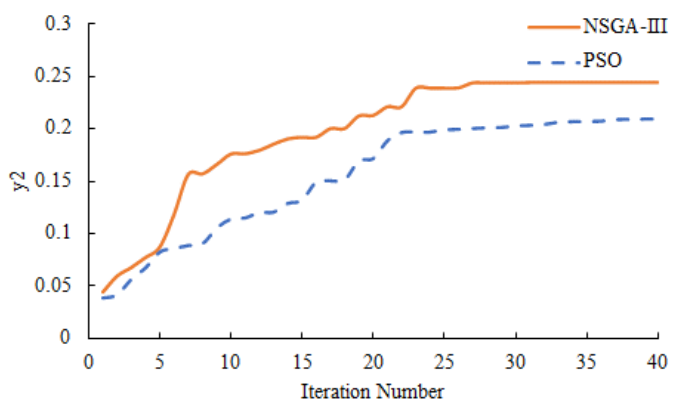

(b) $y 2$

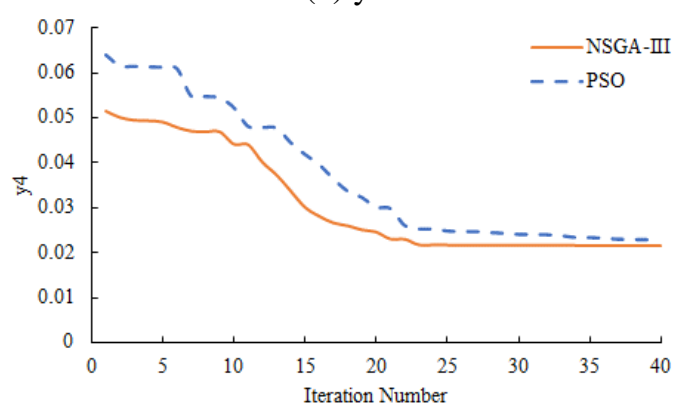

(d) $\mathrm{y} 4$

Fig. 8 The convergence curves of NSGA-III and PSO for 40 generations

The pareto fronts obtained by the two algorithms are shown in Fig. 9, where the red dots are the Pareto Fronts obtained by the NSGA-III algorithm, and the blue triangles are the pareto fronts obtained by the PSO algorithm. From Fig. 9, we can intuitively see that the optimal solution areas obtained by NSGA-III algorithm and PSO algorithm are partially overlapping, indicating that the optimization directions are basically the same. However, the optimal solutions obtained by NSGA-III algorithm are obviously more evenly distributed, while the optimal solutions obtained by PSO algorithm are too continuous, and some of them even converge to a line. Comparatively speaking, the learning strategy of NSGA-III is more effective for the quality optimization problem of the storage tank's bottom.
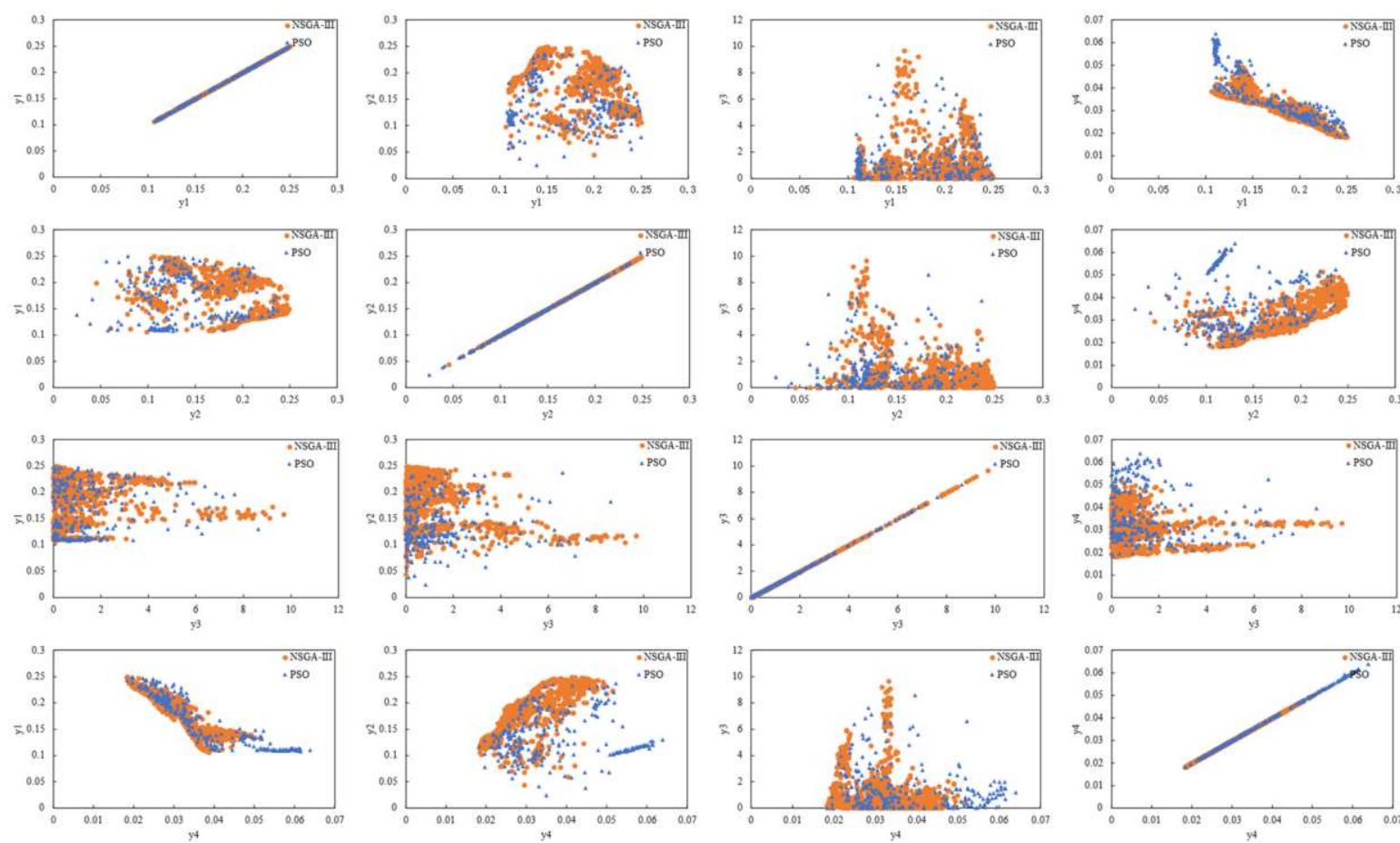

Fig. 9 Pareto fronts of NSGA-III and PSO

In Fig. 9, the four objectives conflict with each other, and the optimal solutions cannot be obtained at 
the same time. And it is difficult for the optimal solutions to compare with each other. Therefore, it is necessary to select several groups of optimization results satisfying the constraint conditions as the optimal solutions according to different preferences. In order to verify the accuracy of the results, we select a group of optimal solutions from the optimization results for simulation verification. Table 4 is comparison table includes optimization results based on NSGA-III algorithm and simulation results. It can be seen from the table that absolute errors of the optimization values obtained by NSGA-III algorithm are both within the allowable range, indicating that the optimization results are accurate.

Table 4 Confirmation test using the obtained optimal process parameters by NSGA-III and PSO

\begin{tabular}{cccccc}
\hline $\begin{array}{c}\text { Optimization } \\
\text { algorithm }\end{array}$ & $\begin{array}{c}\text { optimization } \\
\text { objective }\end{array}$ & $\begin{array}{c}\text { Combination of process } \\
\text { parameters }\end{array}$ & $\begin{array}{c}\text { Optimal } \\
\text { value }\end{array}$ & $\begin{array}{c}\text { Simulation } \\
\text { value }\end{array}$ & $\begin{array}{c}\text { Absolute } \\
\text { error }\end{array}$ \\
\hline \multirow{4}{*}{ NSGA-III } & y1 & & 0.1466 & 0.1591 & $8.53 \%$ \\
& $y 2$ & $(2.25,0.619,1397.8,58.7)$ & 0.1357 & 0.1496 & $10.24 \%$ \\
& $y 3$ & & 1.7 & 1.57 & $7.65 \%$ \\
& $y 4$ & & 0.0346 & 0.0374 & $7.49 \%$ \\
\hline
\end{tabular}

Compared to the quality of the tank bottom before optimization, all quality indexes have been improved after optimization, and the specific results can be seen in Fig. 10. As can be seen from the Fig. 10 , the minimum wall thickness before optimization is $6.25 \mathrm{~mm}$, and after optimization it becomes $6.727 \mathrm{~mm}$. Before optimization, the wrinkle height of flange edge is $16.602 \mathrm{~mm}$, after optimization, it becomes $1.566 \mathrm{~mm}$. The strain distribution of all the units on the tank bottom before and after optimization is shown in Fig. 10 (e). It is obvious that the whole unit has moved to the safe area after optimization.

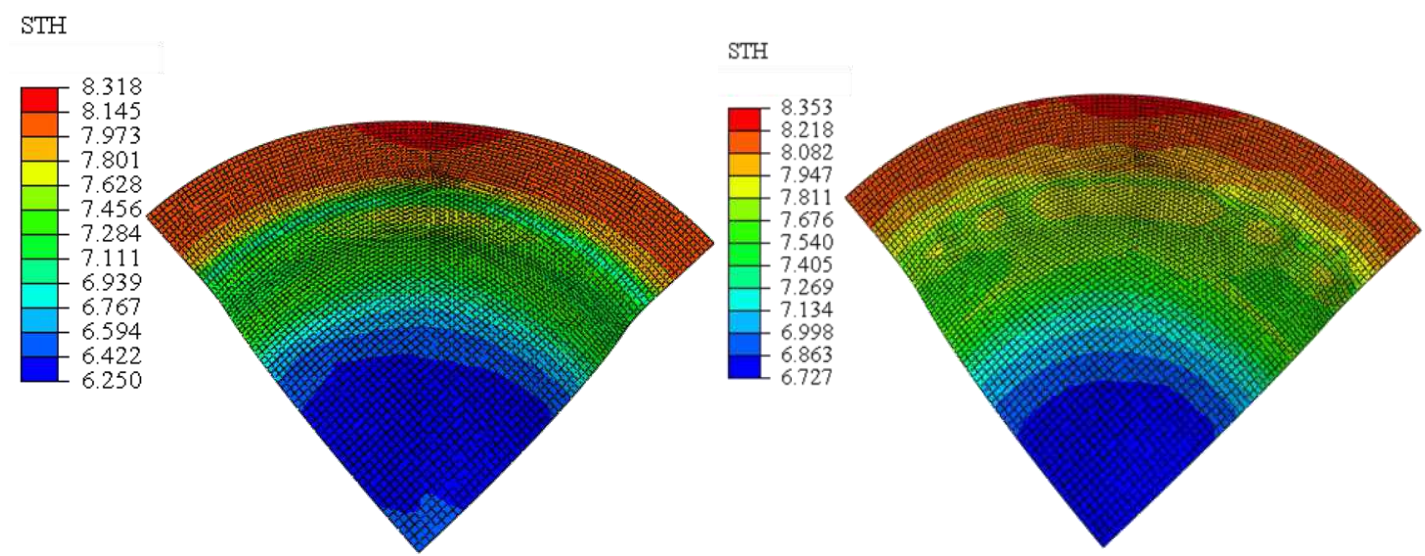

(a) Thickness distribution cloud map before (b) Thickness distribution cloud map after

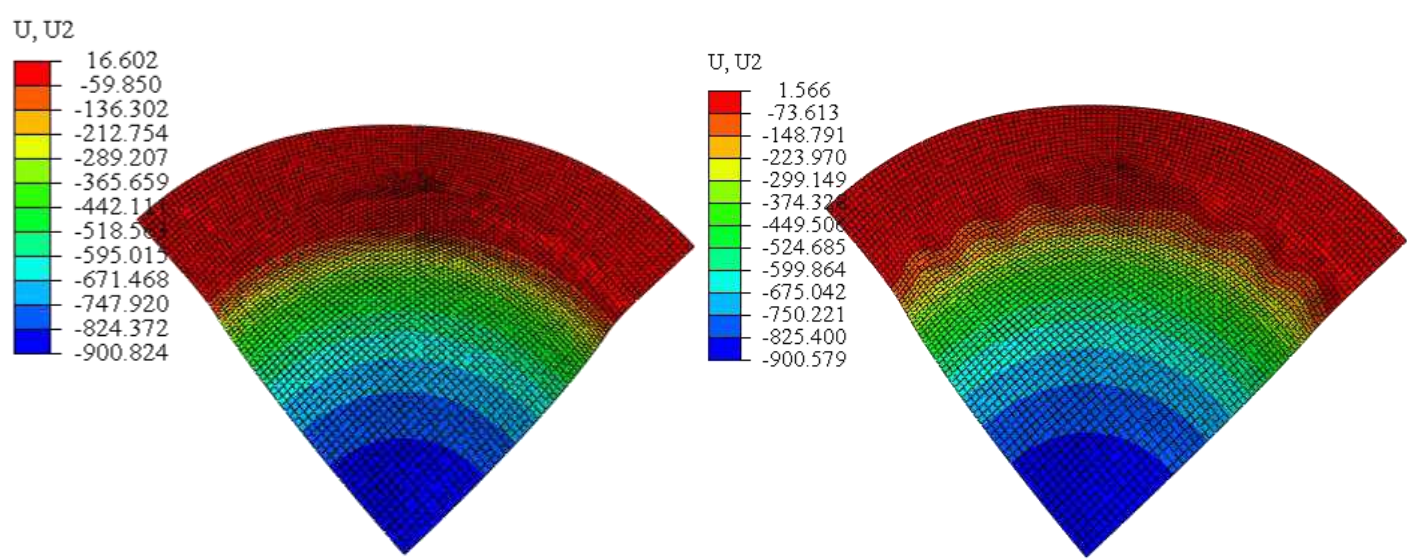

(c) U2 contour distribution cloud map before (d) U2 contour distribution cloud map after 


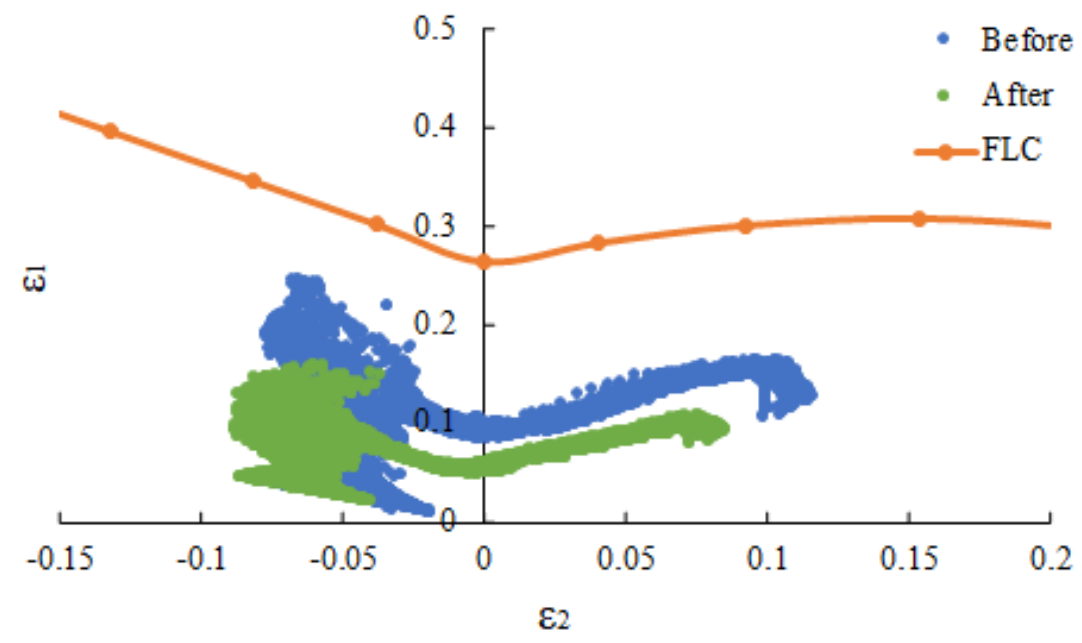

(e) The strain distribution of the points on the forming parts

Fig. 10 Comparison diagram of optimization results

\section{Conclusion}

In this paper, we firstly studied the hydroforming process parameter optimization of storage tank's bottom, then the problem is expounded and mathematic definition is given. Combing with Kriging interpolation method and finite element simulation, the hydroforming process of storage tank's bottom is simulated and a surrogate model is established. The influence of pre-swelling pressure, hydraulic pressure, blank holder force and fillet radius of blank holder on forming quality is discussed by using pareto diagram analysis method. The optimization for hydroforming parameters of storage tank's bottom is settled by NSGA-III and PSO algorithms. By using the two optimization methods, the optimum process parameters with the best quality of forming parts are found, and the optimization results are verified by simulation experiments. The results showed that:

(1) Using Kriging interpolation method to establish a surrogate model can more accurately simulate the relationship between process parameters and quality criteria.

(2) The influence of hydraulic pressure on the forming quality about storage tank's bottom is the largest among the four process parameters, while the other process parameters are not the most effective parameters.

(3) By comparing the results obtained by NSGA-III and PSO optimization algorithms, it can be concluded that NSGA-III algorithm is more effective in the optimization for the hydroforming process parameters of storage tank's bottom. And the optimization results can be obtained faster in the same number of iterations. The effectiveness and accuracy of the optimization results are verified by simulation experiments. It is instructive to select hydroforming technological parameters of storage tank's bottom in future engineering.

Although the hydroforming process parameters of the storage tank's bottom are optimized, and achieved some research results, there is still some work remains to be further studied:

(1) The four objective functions, including biggest wall thickness reduction ratio, cracking factor, height of flange wrinkling, wrinkling factor, represent wrinkling and cracking defects. However, the springback defect also occurs in SHF, and this defect needs to be studied for that storage tank's bottom requires high reliability

(2) The study of fluid pressure and pre-bulging pressure is based on the linear loading path. In fact, there are many different load paths such as pulsating pressure, arc pressure and so on. The influence of different loading paths on forming quality remains to be studied.

Availability of data and material Not applicable

Funding Not applicable

Acknowledgments Not applicable

Declarations

Ethics approval Not applicable 
Consent to participate Not applicable

Consent for publication Not applicable

Competing interests Not applicable

Code availability Not applicable

\section{References}

1. Bell, C., Corney, J., Zuelli, N., \& Savings, D. (2019). A state of the art review of hydroforming technology Its applications, research areas, history, and future in manufacturing. International Journal of Material Forming,13(5):789-828. doi:10.1007/s12289-019-01507-1.

2. Munoz-Rubio, A., Bienvenido-Huertas, D., Bermudez-Rodriguez, F. J. \& Tornell-Barbosa, M. (2019). Design Optimization of the Aeronautical Sheet Hydroforming Process Using the Taguchi Method. Applied Sciences-Basel,9(9). doi:10.3390/app9091932.

3. Ballikaya, H., Savas, V. \& Ozay, C. (2020). The limit drawing ratio in die angled hydromechanical deep drawing method. International Journal of Advanced Manufacturing Technology,106(1-2):791-801. doi:10.1007/s00170-019-04624-y.

4. Safari, M. \& Joudaki, J. (2020). Process parameters selection in manufacturing of sharp conicalparts based on Taguchi design of experiments. Sadhana-Academy Proceedings in Engineering Sciences,45(1):1-12. doi:10.1007/s12046-020-01371-9.

5. Ablat, M. A. \& Qattawi, A. (2017). Numerical simulation of sheet metal forming: a review. International Journal of Advanced Manufacturing Technology,89(1-4):1235-1250. doi:10.1007/s00170-016-9103-5.

6. Alizad-Kamran, M. \& Hoseinpour-Gollo, M. (2017). Theoretical and experimental investigation of hydro-mechanical deep drawing of hemi-prolate spheroid cups. Journal of the Brazilian Society of Mechanical Sciences and Engineering,39(12):5181-5194. doi:10.1007/s40430-017-0898-2.

7. Modi, B. \& Kumar, D. R. (2019). Optimization of process parameters to enhance formability of AA 5182 alloy in deep drawing of square cups by hydroforming. Journal of Mechanical Science and Technology,33(11):5337-5346. doi:10.1007/s12206-019-1026-2.

8. Liu W., Xu Y., Chen Y., Yuan S., Hu L., Zhang Z., et al. (2018). Mechanism and Controllingof Wrinkles during Hydroforming of Integral Thin-walled Curved Shell. Journal of Mechanical Engineering,54(9):37-44.

9. Gajjar, N., Modi, B. \& Digavalli, R. K. (2019). Improvement in Accuracy of Failure Prediction in Sheet Hydroforming of Square Cups Using Stress-Based Forming Limit Diagram. Journal of Failure Analysis and Prevention,19(6):1792-1800. doi:10.1007/s11668-019-00780-1.

10. Cai, G., Fu, J., Zhang, D., Yang, J., Yuan, Y., Lang, L., et al. (2020). A Novel Approach to Predict Wrinkling of Aluminum Alloy During Warm/Hot Sheet Hydroforming Based on an Improved Yoshida Buckling Test. Materials,13(5) doi:10.3390/ma13051165.

11. Cai, G., Yang, J., Yuan, Y., Yang, X., Lang, L., Alexandrov, S. (2020). Mechanics analysis of aluminum alloy cylindrical cup during warm sheet hydromechanical deep drawing. International Journal of Mechanical Sciences, 174. doi:10.1016/j.ijmecsci.2020.105556.

12. Chen, D., Xu, Y., Zhang, S., Zhao, Z., El-Aty, A. A., Ma, Y., et al. (2018). Evaluation of numerical and experimental investigations on the hybrid sheet hydroforming process to produce a novel high-capacity engine oil pan. International Journal of Advanced Manufacturing Technology,97(9-12):3625-3636. doi:10.1007/s00170-018-2124-5.

13. Nikhare, C., Weiss, M. \& Hodgson, P. D. (2017). Buckling in low pressure tube hydroforming. Journal of Manufacturing Processes,28:1-10. doi:10.1016/j.jmapro.2017.05.015.

14. Abdelkefi, A., Malecot, P., Boudeau, N., Guermazi, N. \& Haddar, N. (2017). Evaluation of the friction coefficient in tube hydroforming with the "corner filling test" in a square section die. International Journal of Advanced Manufacturing Technology,88(5-8):2265-2273. doi: 10.1007/s00170-016-8945-1.

15. Bagherzadeh, S., Mirnia, M. J. \& Dariani, B. M. (2015). Numerical and experimental investigations of hydro-mechanical deep drawing process of laminated aluminum/steel sheets. Journal of Manufacturing Processes, 18:131-140. doi:10.1016/j.jmapro.2015.03.004.

16. Chen, Y. Z., Liu, W., Zhang, Z. C., Xu, Y. C. \& Yuan, S. J. (2017). Analysis of wrinkling during sheet hydroforming of curved surface shell considering reverse bulging effect. International Journal of Mechanical Sciences, 120:70-80. doi:10.1016/j.ijmecsci.2016.10.023.

17. Wang, C., Wan, M., Meng, B. \&Xu, L. (2017). Process window calculation and pressure locus 
optimization in hydroforming of conical box with double concave cavities. International Journal of Advanced Manufacturing Technology,91(1-4):847-858. doi:10.1007/s00170-016-9814-7.

18. Liu, W., Chen, Y., Xu, Y. \& Yuan, S. (2018). Enhancement on plastic deformation of curved surface shell by sheet hydroforming with optimized pre-bulging process. International Journal of Advanced Manufacturing Technology, 97(9-12):4145-4156. doi:10.1007/s00170-018-2185-5.

19. Ozturk, E., Turkoz, M., Halkaci, H. S. \& Koc, M. (2017). Determination of optimal loading profiles in hydromechanical deep drawing process using integrated adaptive finite element analysis and fuzzy control approach. International Journal of Advanced Manufacturing Technology,88(9-12):2443-2459. doi:10.1007/s00170-016-8912-x.

20. Chebbah, M. S. \& Lebaal, N. (2020). Tube hydroforming optimization using a surrogate modeling approach and Genetic Algorithm. Mechanics of Advanced Materials and Structures, 27(6):515-524. doi:10.1080/15376494.2018.1482578.

21. Bansch, E., Luttmann, A., Montalvo-Urquizo, J., Schmidt, A. \& Villarreal-Marroquin, M. G. (2020). Simulation and multi-objective optimization to improve the final shape and process efficiency of a laser-based material accumulation process. Journal of Mathematics in Industry, 10(1). doi:10.1186/s13362-020-0070-y.

22. Hu, C., Dai, L., Yan, X., Gong, W., Liu, X. \& Wang, L. (2020). Modified NSGA-III for sensor placement in water distribution system. Information Sciences,509:488-500. doi:10.1016/j.ins.2018.06.055.

23. Ben Abdessalem, A. \& El-Hami, A. (2014). Global sensitivity analysis and multi-objective optimisation of loading path in tube hydroforming process based on metamodelling techniques. International Journal of Advanced Manufacturing Technology,71(5-8):753-773. doi:10.1007/s00170-013-5518-4.

24. Ge, Y. L., Li, X. X., Lang, L. H. \& Ruan, S. W. (2017). Optimized design of tube hydroforming loading path using multi-objective differential evolution. International Journal of Advanced Manufacturing Technology,88(1-4):837-846. doi:10.1007/s00170-016-8790-2.

25. Hashemi, A., Hoseinpour-Gollo, M., Seyedkashi, S. M. H. \& Pourkamali-Anaraki, A. (2017). A new simulation-based metaheuristic approach in optimization of bilayer composite sheet hydroforming. Journal of The Brazilian Society of Mechanical Sciences and Engineering,39(10):4011-4020. doi:10.1007/s40430-017-0720-1.

26. Huang, T. L., Song, X. W. \& Liu, M. (2016). A Kriging-based non-probability interval optimization of loading path in T-shape tube hydroforming. International Journal of Advanced Manufacturing Technology,85(5-8):1615-1631. doi:10.1007/s00170-015-8034-X.

27. Intarakumthornchai, T., Aue-U-Lan, Y., Kesvarakul, R. \& Jirathearanat, S. Feasible pressure and axial feed path determination for fuel filler tube hydroforming by genetic algorithm. Proceedings of the Institution of Mechanical Engineers Part B-Journal of Engineering Manufacture,229(4):623-630. doi:10.1177/0954405414559076. 
Figures

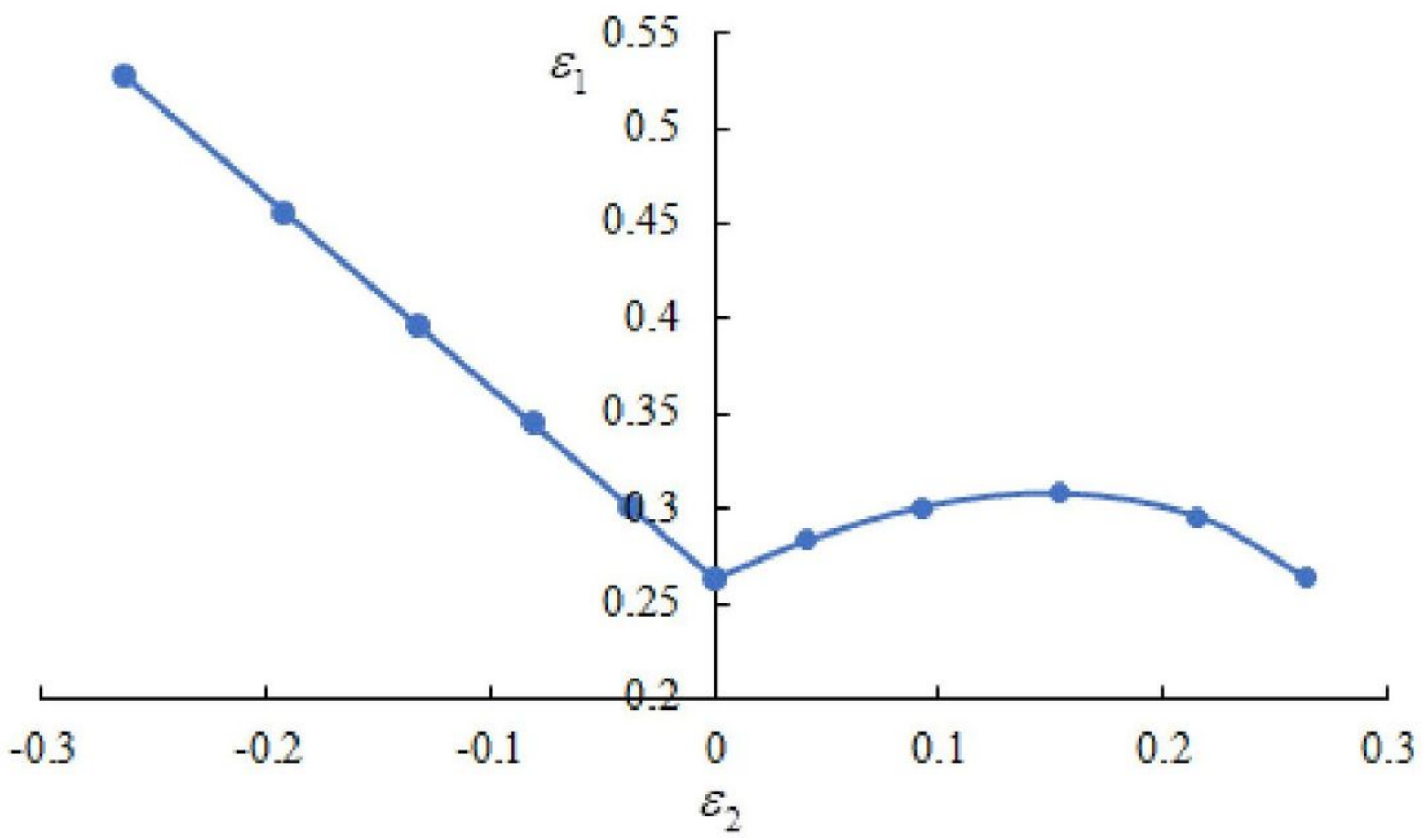

Figure 1

Theoretical FLC of 2219 aluminum alloy 


\section{Start}

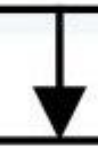

Research space definition

\section{DOE}

Evaluation of the objective functions

\section{Kriging}

Construction of the surrogate model

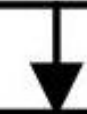

NSGA-III and PSO Algorithm

\section{Best optimum}

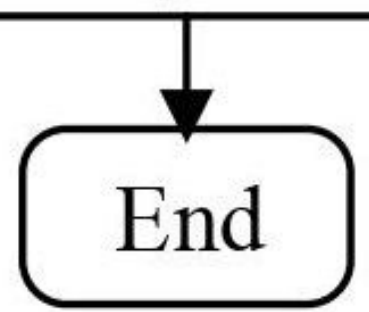

Figure 2

Flowchart of optimized design 


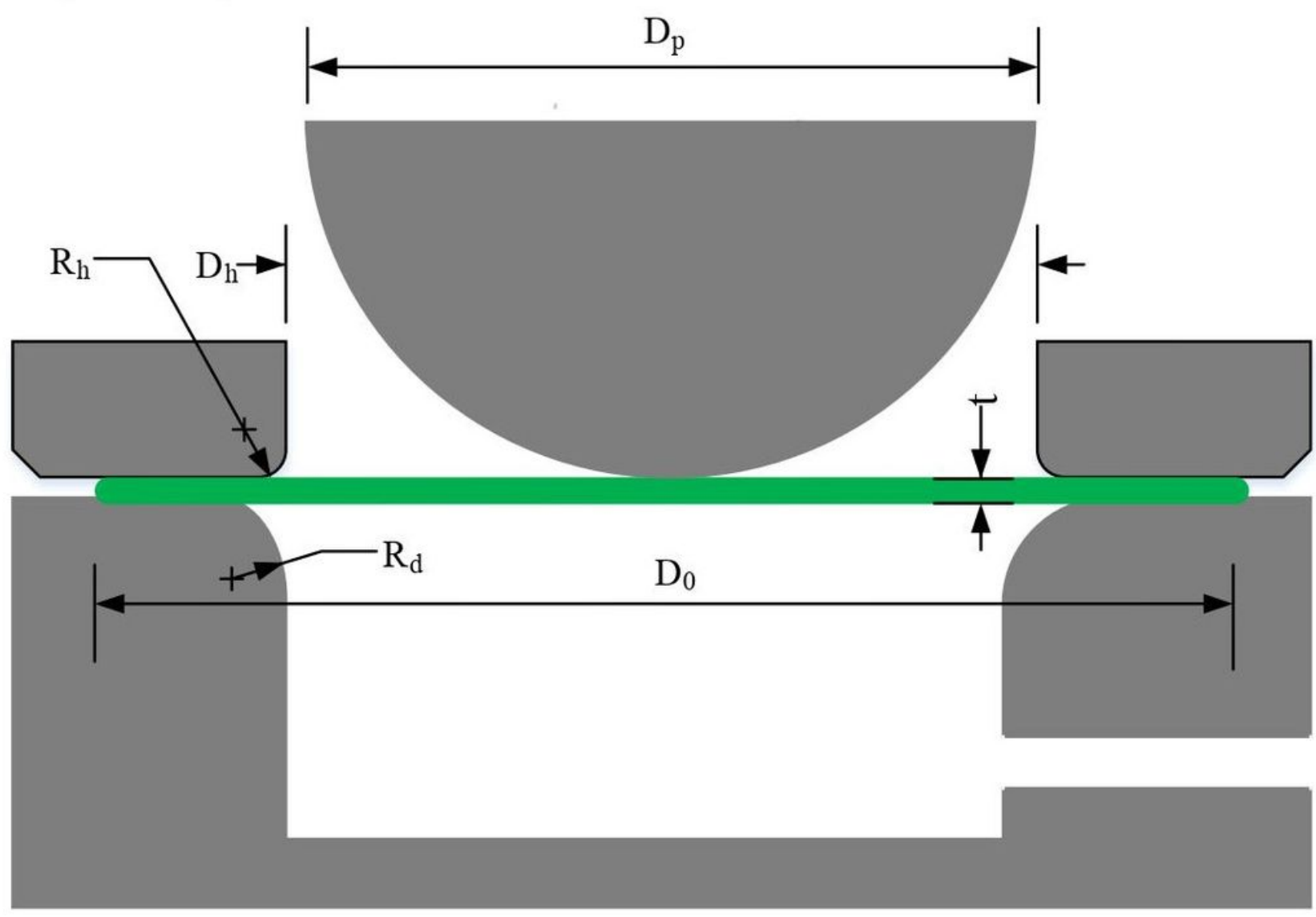

Figure 3

Geometrical parameters of a storage tank's bottom

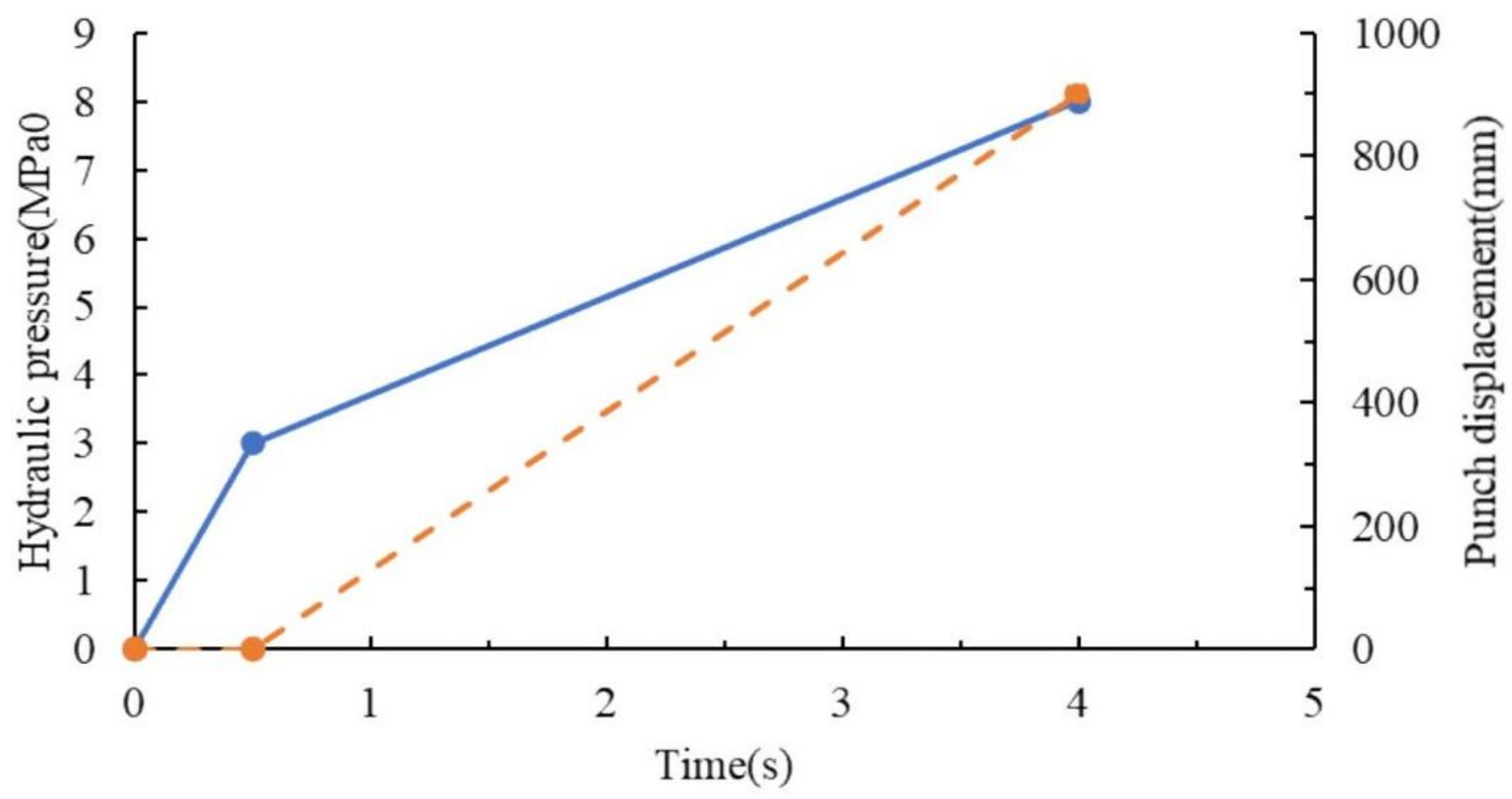

$\longrightarrow$ Hydrodynamic pressure $\quad-\bullet-$ Punch displacement 
Figure 4

Loading path of hydraulic pressure

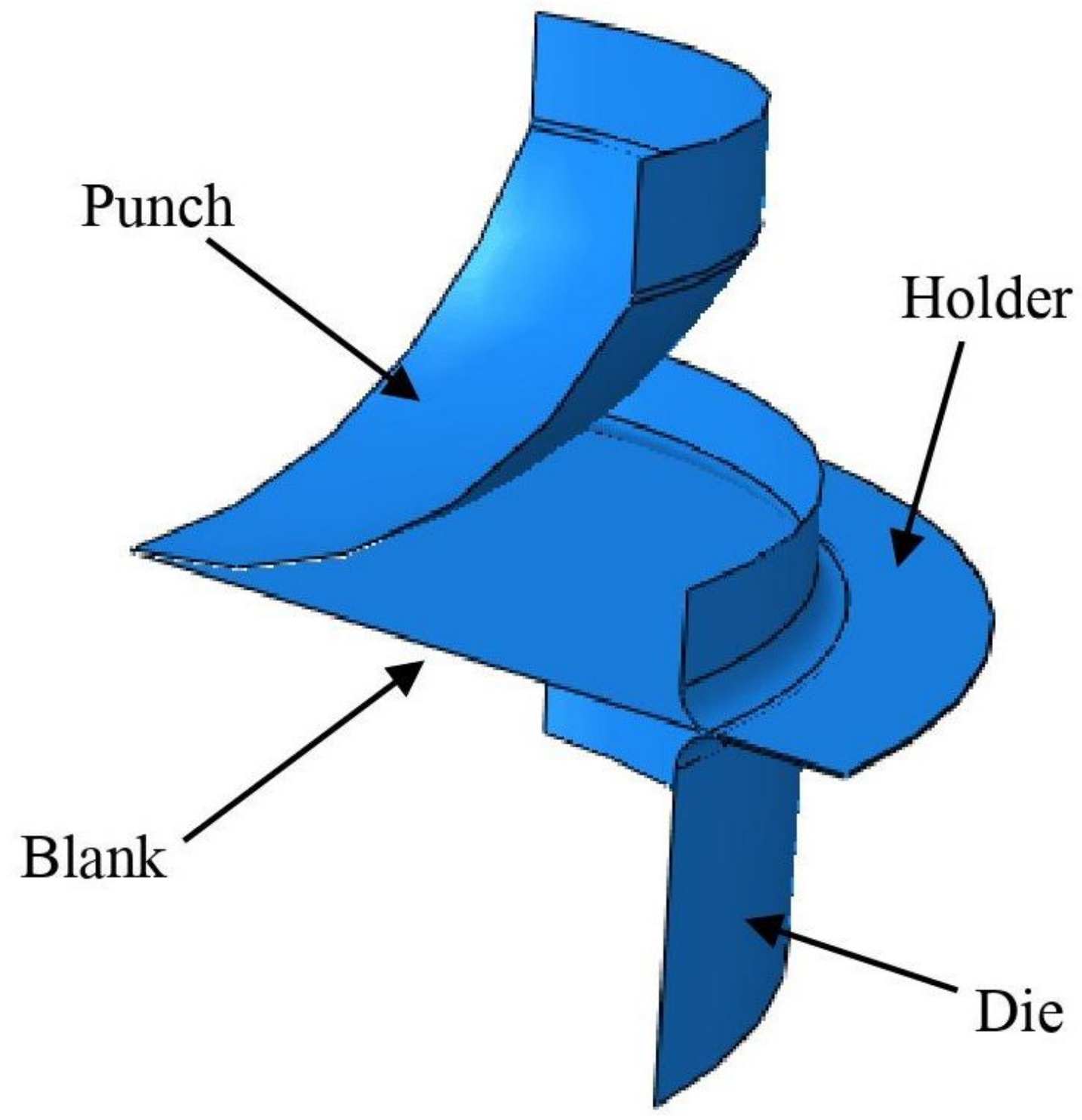

Figure 5

Finite element model of the storage tank's bottom 


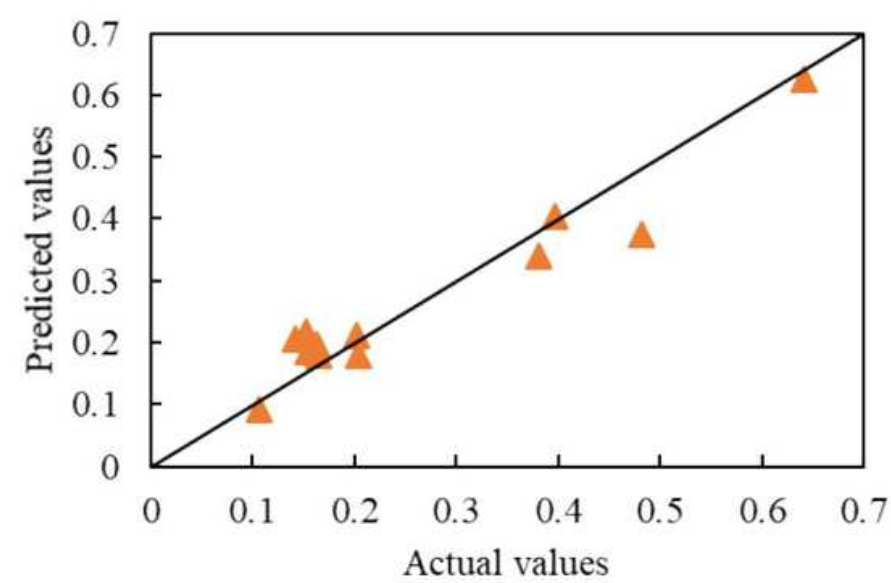

(a) yl

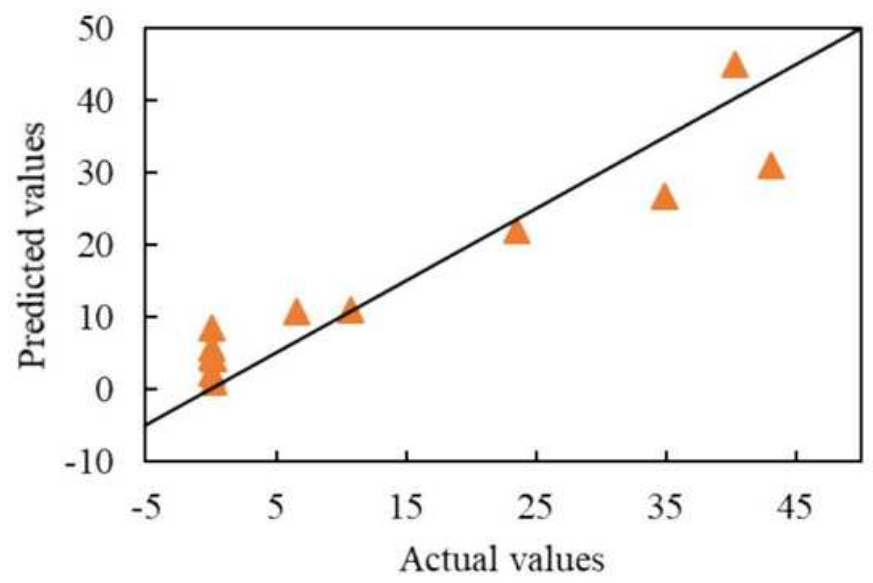

(b) y3

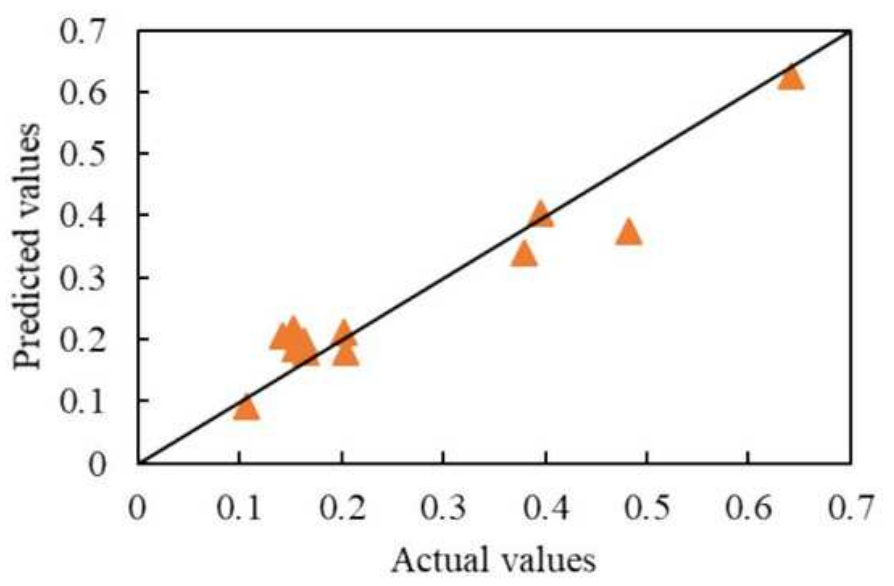

(b) y2

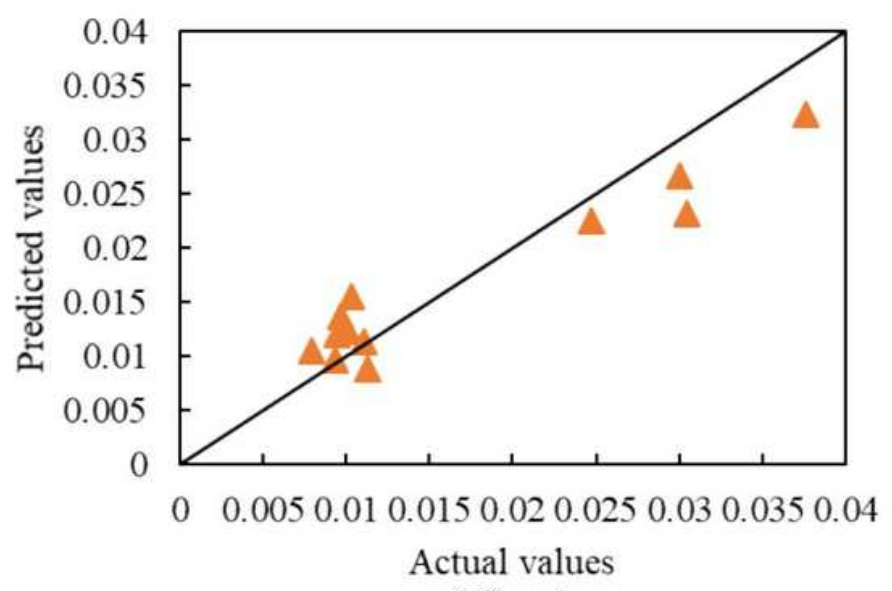

(d) y4

Figure 6

The goodness-of-fit plot of Kriging 


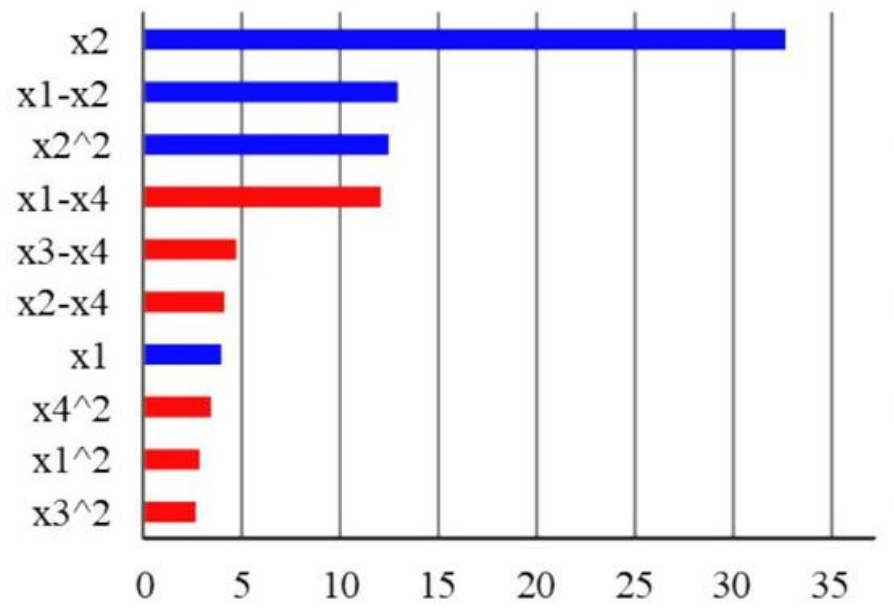

(a) $\%$ effect on $y 1$

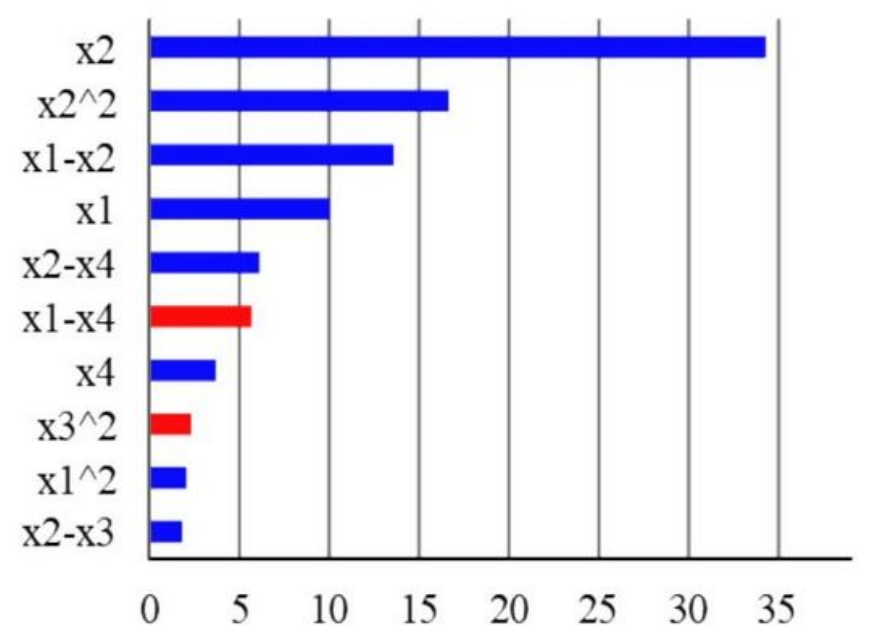

(c) $\%$ effect on y3

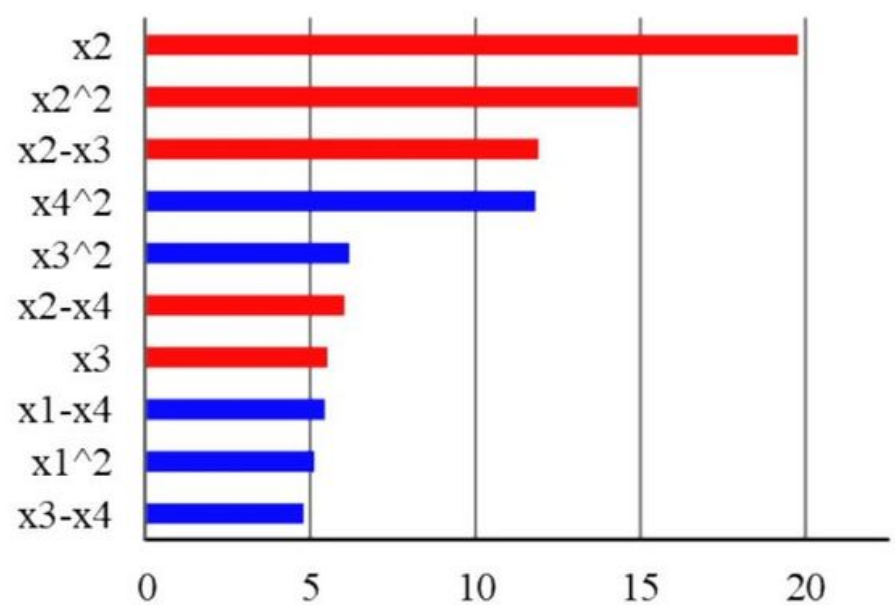

(b) $\%$ effect on y2

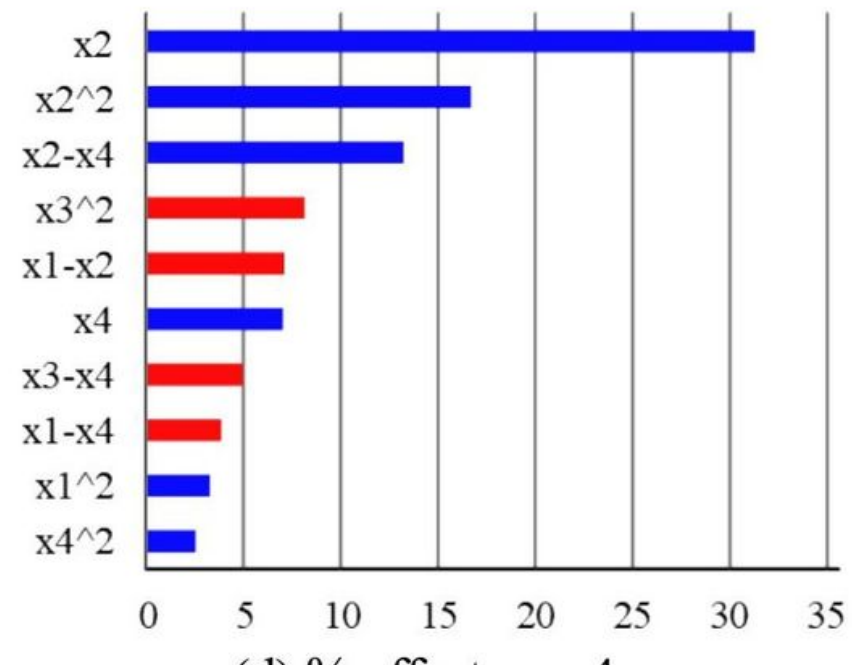

(d) $\%$ effect on y4

Figure 7

Pareto diagram showing the relative influences of process parameters $\mathrm{X}$ on the response variable 


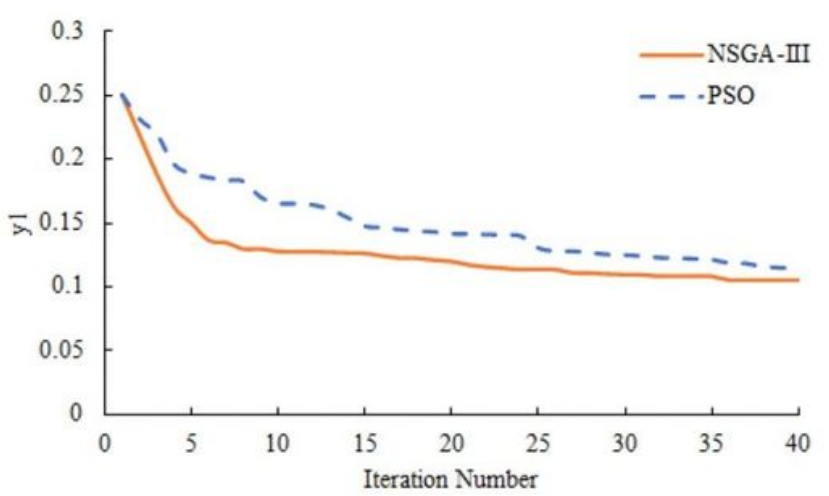

(a) y1

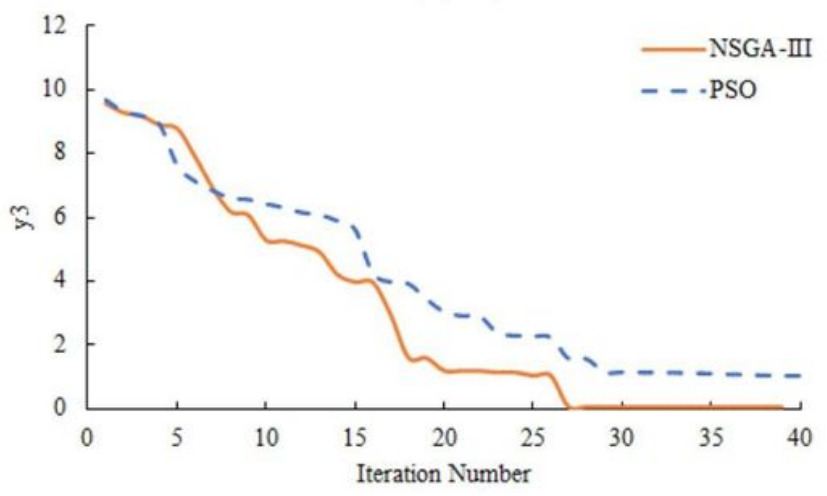

(b) $\mathrm{y} 3$

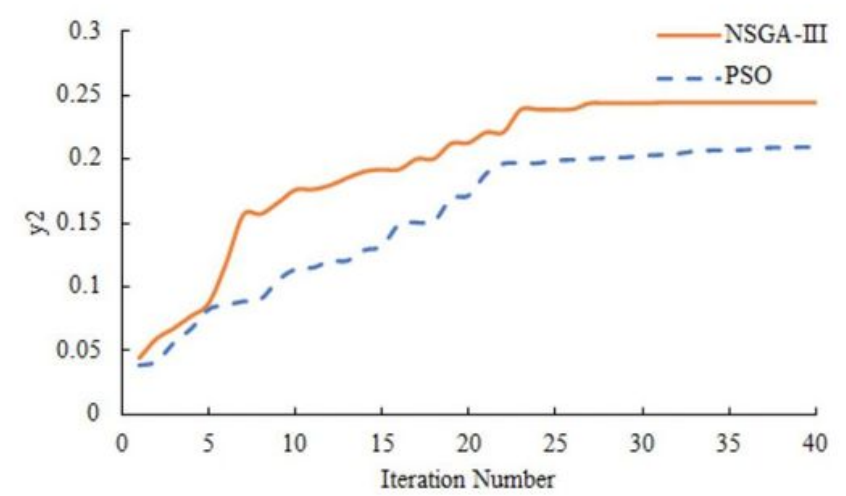

(b) y2

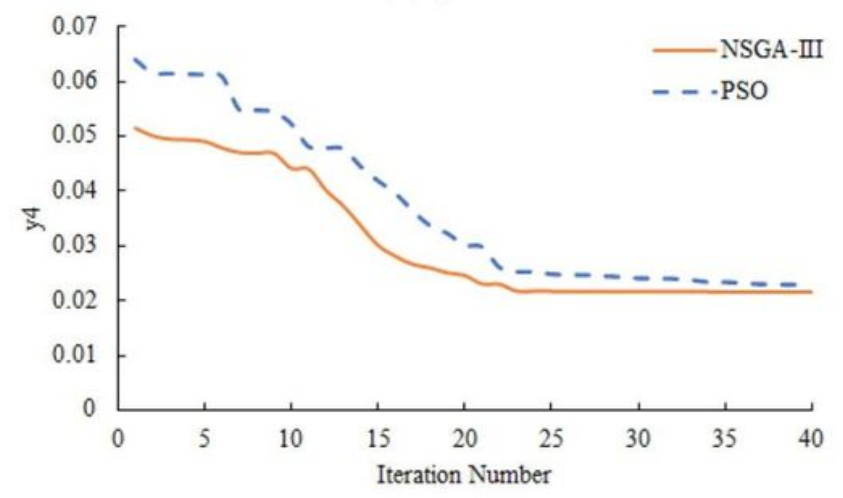

(d) $\mathrm{y} 4$

\section{Figure 8}

The convergence curves of NSGA-III and PSO for 40 generations 

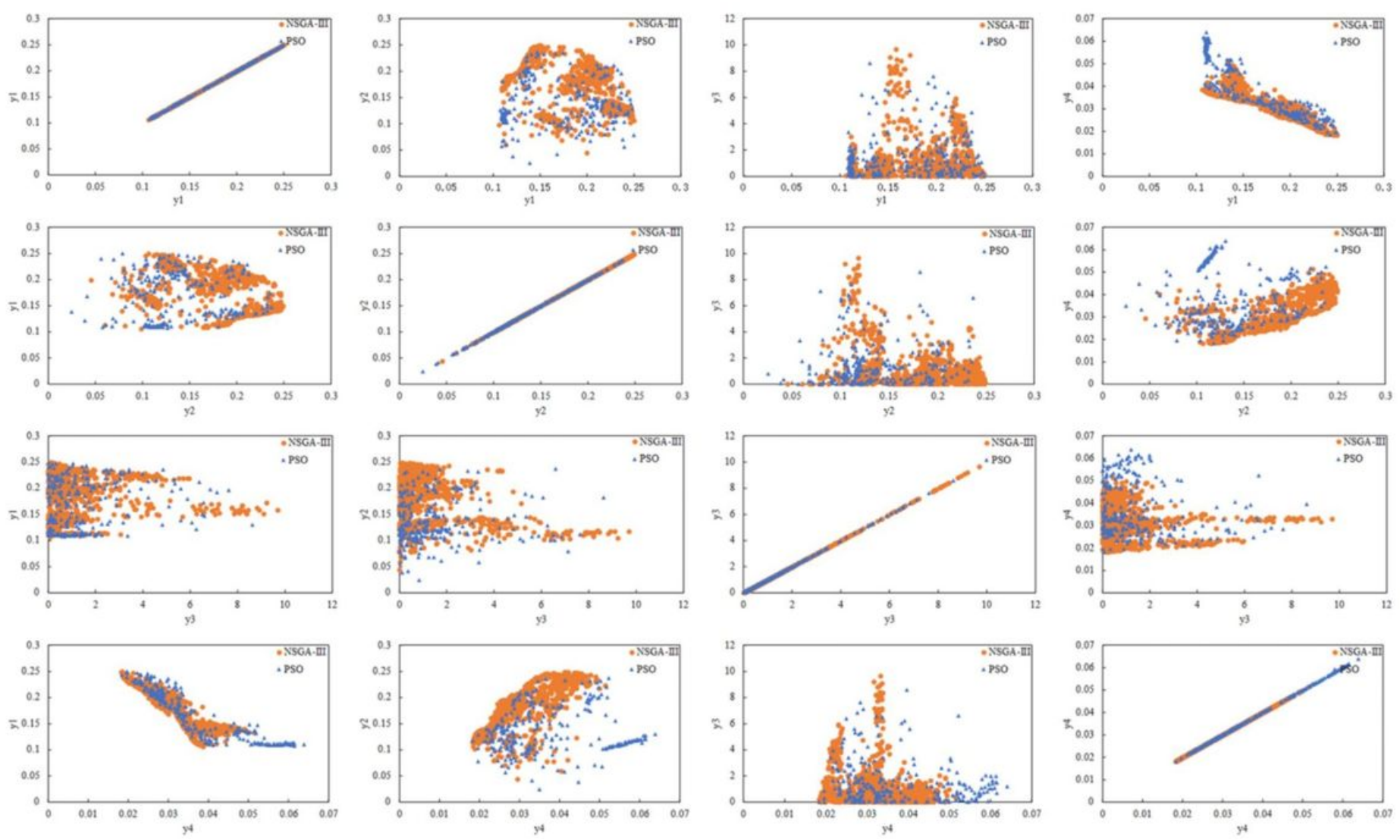

Figure 9

Pareto fronts of NSGA-III and PSO 
STH

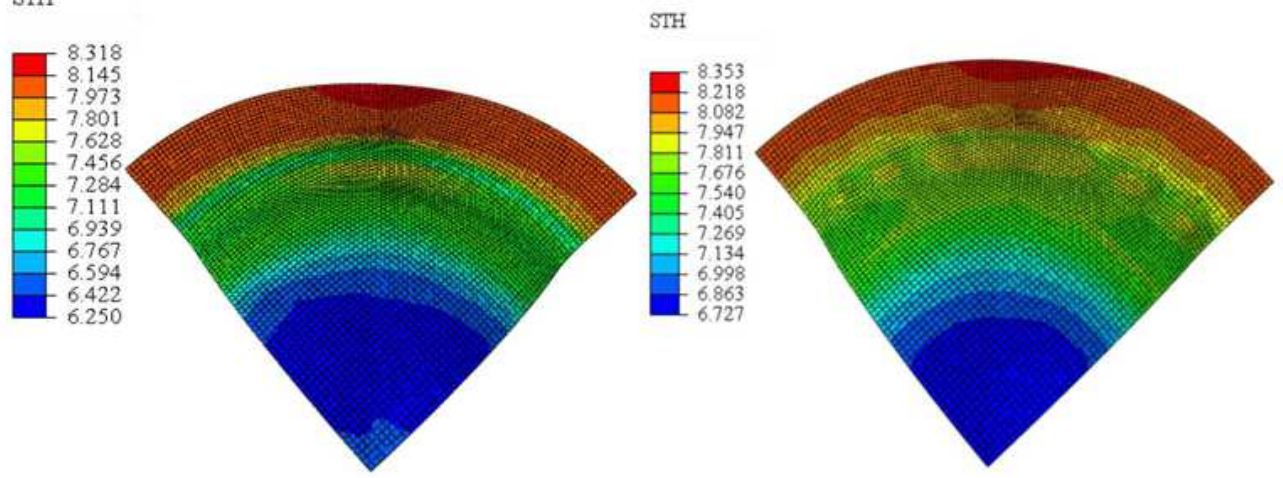

(a) Thickness distribution cloud map before (b) Thickness distribution cloud map after

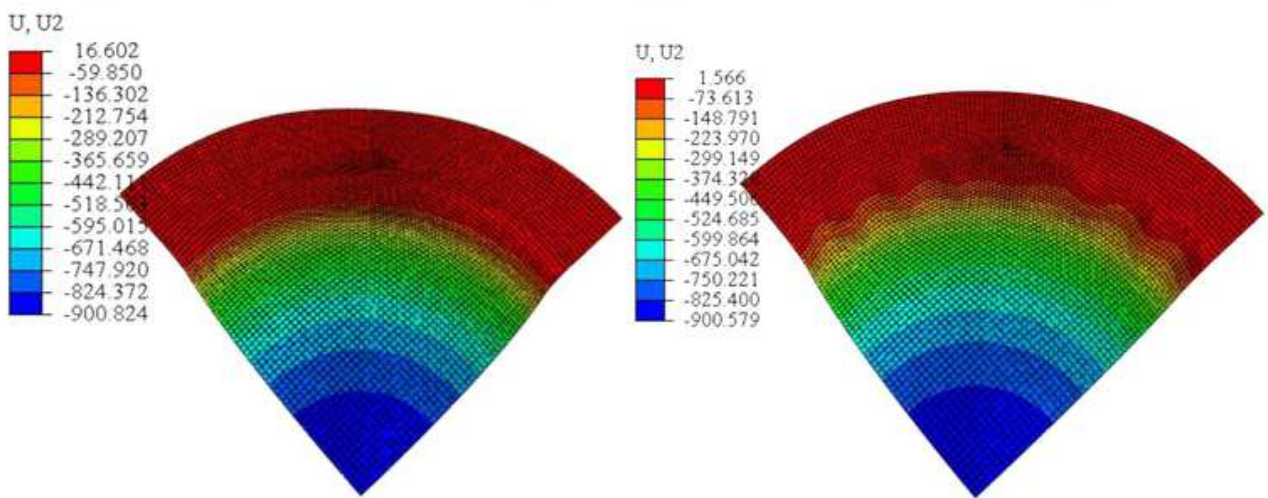

(c) U2 contour distribution cloud map before (d) U2 contour distribution cloud map after

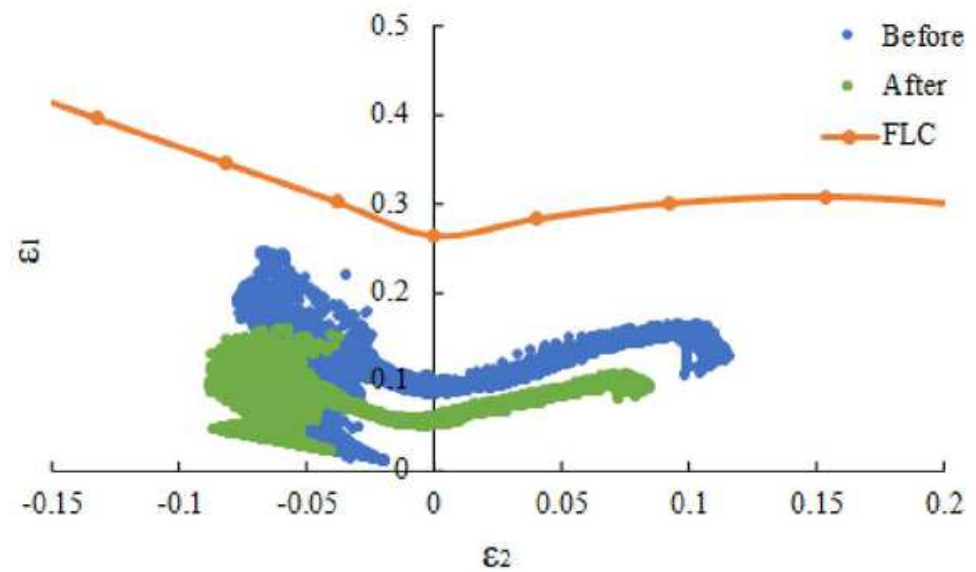

(e) The strain distribution of the points on the forming parts

Figure 10

Comparison diagram of optimization results 